\title{
Integrating ASCAT surface soil moisture and GEOV1 leaf area index into the SURFEX modelling platform: a land data assimilation application over France
}

\author{
A. L. Barbu, J.-C. Calvet, J.-F. Mahfouf, and S. Lafont \\ CNRM-GAME, CNRS - UMR3589, Météo France, Toulouse, France \\ Correspondence to: J.-C. Calvet (jean-christophe.calvet@meteo.fr)
}

Received: 21 May 2013 - Published in Hydrol. Earth Syst. Sci. Discuss.: 11 July 2013

Revised: 24 October 2013 - Accepted: 4 December 2013 - Published: 14 January 2014

\begin{abstract}
The land monitoring service of the European Copernicus programme has developed a set of satellitebased biogeophysical products, including surface soil moisture (SSM) and leaf area index (LAI). This study investigates the impact of joint assimilation of remotely sensed SSM derived from Advanced Scatterometer (ASCAT) backscatter data and the Copernicus Global Land GEOV1 satellitebased LAI product into the the vegetation growth version of the Interactions between Soil Biosphere Atmosphere (ISBAA-gs) land surface model within the the externalised surface model (SURFEX) modelling platform of Météo-France. The ASCAT data were bias corrected with respect to the model climatology by using a seasonal-based CDF (Cumulative Distribution Function) matching technique. A multivariate multi-scale land data assimilation system (LDAS) based on the extended Kalman Filter (EKF) is used for monitoring the soil moisture, terrestrial vegetation, surface carbon and energy fluxes across the domain of France at a spatial resolution of $8 \mathrm{~km}$. Each model grid box is divided into a number of land covers, each having its own set of prognostic variables. The filter algorithm is designed to provide a distinct analysis for each land cover while using one observation per grid box. The updated values are aggregated by computing a weighted average.

In this study, it is demonstrated that the assimilation scheme works effectively within the ISBA-A-gs model over a four-year period (2008-2011). The EKF is able to extract useful information from the data signal at the grid scale and distribute the root-zone soil moisture and LAI increments throughout the mosaic structure of the model. The impact of the assimilation on the vegetation phenology and on the
\end{abstract}

water and carbon fluxes varies from one season to another. The spring drought of 2011 is an interesting case study of the potential of the assimilation to improve drought monitoring. A comparison between simulated and in situ soil moisture gathered at the twelve SMOSMANIA (Soil Moisture Observing System-Meteorological Automatic Network Integrated Application) stations shows improved anomaly correlations for eight stations.

\section{Introduction}

Monitoring the seasonal and interannual variability of the water and carbon cycles over land is needed for many applications, including hydrological and climate studies. The possibility of improving the performance of land surface models (LSM) using remotely sensed observations is a field of active research. The mechanism of integrating observations into a numerical model in a statistically optimal way is called data assimilation. Data assimilation allows for the improvement of the representation of the dynamical behaviour of a biogeophysical system.

There is a large interest in using a multivariate data assimilation system as an unifying context in which various types of observations from different sources are integrated in a complex model. From the theoretical point of view, the more information a system gets, the better the resulting analysis. In practice, due to the inherent uncertainties in the observations as well as in the models, the analysis is often not optimal. The multivariate data assimilation approach imposes additional constraints on the system to make it fit the observations 
and prevent it from being too close to the observations for wrong reasons (such as an underestimation of the observation uncertainty).

Moreover, the complementary nature of different types of data has been highlighted in Kaminski et al. (2012) and Kato et al. (2013) by the consideration of various pairs of observations (fraction of absorbed photosynthetically active radiation (fAPAR) and atmospheric $\mathrm{CO}_{2}$ or fAPAR and latent heat fluxes, respectively). The two teams of researchers pointed out the necessity of considering the assimilation of multiple data streams as an approach that is more appropriate for representing the complexity of physical phenomena and more robust for the identification of model and data biases.

Land data assimilation systems (LDAS) are needed to integrate various satellite data providing information about land state variables such as the surface soil moisture (SSM) and leaf area index (LAI) into LSM.

Soil moisture is a key factor in controlling both water and energy cycles (through its impact on the fluxes partitioning at the surface). In addition, it is linked to the carbon cycle through the coupling between plant transpiration and photosynthesis. A number of studies have discussed the importance of soil moisture in the description of the carbon cycle whose connexions with the hydrological cycle are largely unknown (van der Molen et al., 2011). Moreover, in the context of the global warming trend, the soil water availability may play a role in ecosystem carbon fluxes far more important than considered until now (Reichstein et al., 2007). Assimilating remotely sensed SSM data into a LSM has been proved, in a large number of papers, to be effective in estimating deeper soil moisture in various contexts, such as hydrology (Houser et al., 1998; Reichle et al., 2002a; Draper et al., 2011), numerical weather prediction (NWP) (Mahfouf et al., 2010; Dharssi et al., 2011; De Rosnay et al., 2013) and agricultural studies (Bolten and Crow, 2012).

Also, LAI impacts the exchanges of water vapour and $\mathrm{CO}_{2}$ between the vegetation canopy and the atmosphere. A number of studies (Jarlan et al., 2008; Gu et al., 2006; Demarty et al., 2007) have shown the potential of assimilating LAI observations to correct vegetation model states.

Recognising the importance of better exploiting the close link between soil moisture and vegetation variables, scientists made efforts to implement multivariate data assimilation schemes into complex models such as coupled hydrological and crop models or physiologically based LSM. The possibility of combining these two data streams within such models has been explored in several data assimilation applications either by setting observing system simulation experiments (Pauwels et al., 2007; Nearing et al., 2012) or by monitoring real environments (Sabater et al., 2008; Barbu et al., 2011).

This study is placed in the context of multivariate multiscale data assimilation (MVMS DA) within an externalised surface (SURFEX) modelling platform of Météo-France, after a nomenclature used in Montzka et al. (2012). Several types of data at various spatial scales may be simultaneously incorporated into a LSM using the extended Kalman Filter (EKF) (Mahfouf et al., 2009). Different versions of the EKF technique were used in various studies in order to assimilate either soil moisture (Draper et al., 2009), LAI (Jarlan et al., 2008), or both LAI and soil moisture (Sabater et al., 2008; Barbu et al., 2011).

This study is an extension of a previous work by Barbu et al. (2011) in which the joint assimilation of ground-based soil moisture and LAI observations was investigated at a local scale. While in situ data are limited by their spatial coverage, EO (Earth observation) satellite observations, representing a significant source of information, provide consistent data over large areas with a full spatial coverage. A wide range of satellite-based biophysical products have been developed within the FP7 Geoland2 project (http://www. gmes-geoland.info) as a key component of the Copernicus Global Land Service. It is an European initiative set up to operationally provide a set of biophysical variables describing the terrestrial vegetation and the water and energy budgets. This work evaluates, on the scale of France, the use of two satellite-based products provided by the Copernicus Global Land Service, namely SSM product retrieved from the scatterometer ASCAT together with GEOV1 LAI data in the vegetation growth version of the Interactions between Soil Biosphere Atmosphere model (ISBA-A-gs) (Calvet et al., 1998). The period under investigation extends over four years, from 2008 to 2011, and includes various climatic conditions. In particular, the spring drought of 2011 is analysed.

The main objectives of this study are to assess to what extent the LDAS is able to (1) simultaneously ingest EO satellite data providing mixed signals at a grid-scale into the mosaic structure of ISBA-A-gs; (2) propagate information from the surface into the root-zone soil layer; (3) consistently impact the water and carbon fluxes; (4) improve the short-term vegetation response to drought conditions.

The ISBA-A-gs LSM, the observational data sets and the data assimilation scheme are described in Sect. 2. The LDAS configuration is presented in Sect. 3. In Sect. 4 the results are presented at the country scale, as well as over specific grid cells. The impact of the assimilation on LAI, soil moisture, water and carbon fluxes is presented in Sect. 4.3. Section 5.1 describes the impact of the assimilation on the monitoring of the drought of spring 2011. The verification of the assimilation impact on the root-zone soil moisture is performed using ground-based observations in Sect. 5.2. Finally, Sect. 6 summarises the main conclusions of the study.

\section{The LDAS}

In this study, the LDAS is defined as an offline sequential data assimilation system based on a LSM uncoupled with the atmosphere. The LDAS is able to integrate simultaneously available SSM and LAI observations at a given 
time step into the ISBA-A-gs LSM aiming at adjusting the model trajectory at that time. The experiments were conducted with the SURFEX modelling platform (Le Moigne et al., 2009) developed at Météo-France, which represents the sub-grid vegetation heterogeneity (crops, grasslands, coniferous forests, broadleaf forests) by using a mosaic approach (Koster and Suarez, 1992). The model is driven by observation-based atmospheric forcing data which are derived from the SAFRAN (Système d'Analyse Fournissant des Renseignements Atmosphériques à la Neige) mesoscale analysis system at $8 \mathrm{~km}$ spatial resolution and hourly temporal sampling (Quintana-Segui et al., 2008). Atmospheric variables include precipitation, $2 \mathrm{~m}$ air temperature, $2 \mathrm{~m}$ specific humidity, wind speed, surface pressure, incoming solar radiation, and incoming long-wave radiation.

The three main components of the LDAS (land surface model, remote sensing data and analysis scheme) are detailed hereafter.

\subsection{The ISBA-A-gs LSM}

In the SURFEX platform (http://www.cnrm.meteo.fr/ surfex/), the ISBA LSM (Noilhan and Mahfouf, 1996) describes the exchanges between soil, vegetation and atmosphere. In this study, version 7.2 of SURFEX is used.

The force-restore three-layer version of the soil model in ISBA is used in this study (Boone et al., 1999). The soil texture parameters (clay and sand proportions) are taken from the soil geographical database (BDGSF) of the French National Institute of Agronomic Research available at http: //www.gissol.fr/programme/bdgsf/. For each model grid cell, the modelled soil moisture is partitioned into three variables: the simulated SSM (representative of the first soil centimetre), the volumetric root-zone soil moisture WG2 (defined for rooting depths depending on the vegetation type, with a maximum thickness of $2.5 \mathrm{~m}$ ) and a volumetric soil moisture value WG3 in the recharge zone below the plant roots (with a maximum thickness of $1 \mathrm{~m}$ ). Hereafter, the simulated SSM will be referred to as SSMmod. In the model, the propagation of surface information to root-zone layer relies on the force-restore dynamics of the model; SSMmod is forced by precipitation and evaporation and restored toward WG2.

The A-gs module of ISBA was developed to allow the simulation of photosynthesis and the growth of vegetation with different biomass reservoirs (Calvet et al., 1998). The linear relationship between the active biomass and LAI (defined as the green leaf area per unit ground horizontal surface area) is expressed as

$B_{\mathrm{a}}=\beta \cdot \mathrm{LAI}$,

where $\beta$ may depend upon vegetation type, nitrogen supply and climate. The vegetation biomass and LAI variables are governed by photosynthesis and evolve dynamically in response to weather and climate conditions. Namely, during the growing phase, the net assimilation of $\mathrm{CO}_{2}$ photosynthesis leads to plant growth from a minimum threshold set to either $1 \mathrm{~m}^{2} \mathrm{~m}^{-2}$ for coniferous forest or $0.3 \mathrm{~m}^{2} \mathrm{~m}^{-2}$ for other vegetation types. A deficit of photosynthesis sets off leaf biomass mortality that exceeds net assimilation. Consequently, LAI drops down to its minimum value.

The photosynthetic activity depends on the vegetation types. The input soil and vegetation parameters are provided by the ECOCLIMAP-II global database (Faroux et al., 2013) which describes ecosystem classes and assigns them to twelve elementary land-cover types (patches) at $1 \mathrm{~km}$ spatial resolution. Three of them represent patches without vegetation (bare soil, permanent snow and rocks). Over the domain of France, the dominant ecosystems are grasslands (31\%), C3 croplands (24\%), deciduous forest $(20 \%)$, coniferous forests $(11 \%)$ and $\mathrm{C} 4$ croplands $(4 \%)$. Bare soil represents $8 \%$ of the area. The mean root depths are of $1.5 \mathrm{~m}$ for herbaceous vegetation and $2 \mathrm{~m}$ for forests.

The water and energy budgets are calculated separately for each patch. ISBA-A-gs simulates the aggregation of carbon, water and energy fluxes from the different patches. The modelled LAI at $8 \mathrm{~km}$ resolution is an average value of vegetation types (up to 9 in the current configuration) weighted with their cover fraction.

The ISBA A-gs model simulates the interaction between water and carbon cycles. The evapo-transpiration flux (ET) represents the sum of the evaporation of liquid water from the soil surface and from the vegetation, and the sublimation from the snow and soil ice. The net ecosystem $\mathrm{CO}_{2}$ exchange (NEE) is given by the difference between the ecosystem respiration (RECO) and gross primary production (GPP). The GPP represents the carbon uptake by photosynthesis. The RECO value departs from a basal rate as a function of soil temperature and soil moisture (Albergel et al., 2010). Following Lafont et al. (2012) the respiration basal rate was calibrated by assuming an equilibrium between the ecosystem respiration and the vegetation carbon uptake over the whole $4 \mathrm{yr}$ period of the simulations.

Also, the A-gs module features two different types of the plant response to drought, for both herbaceous vegetation (Calvet, 2000) and forests (Calvet et al., 2004). In the strategy called defensive or drought-avoiding, the plant increases the water use efficiency (WUE) in response to soil water stress, while in the offensive or drought-tolerant strategy, the WUE is stable or even decreases. While C 3 crops and coniferous trees are associated with a drought-avoiding behaviour, $\mathrm{C} 4$ crops, grasslands and broadleaf trees are associated with a drought-tolerant behaviour (Calvet et al., 2012, 2004).

\subsection{Remote-sensing data sets}

\subsubsection{Satellite-derived SSM}

The Advanced Scatterometer (ASCAT) is an active C-band microwave sensor on board the European MetOp polarorbiting satellite. The soil moisture information is derived 
from ASCAT radar backscatter coefficients delivered at $25 \mathrm{~km}$ resolution using a methodology developed at the Vienna University of Technology (TU-Wien). This method is based on a change detection approach originally developed for the active microwave instrument flown on-board the European satellites ERS-1 and ERS-2 (Wagner et al., 1999; Bartalis et al., 2007). An exponential filter in its recursive formulation (Albergel et al., 2008) is applied to this SSM product to estimate the soil water index (SWI) using a timescale parameter $T$ that may vary between 1 day and 100 days. The result for the top soil moisture content $(<5 \mathrm{~cm})$ range between 0 (dry) and 1 (saturated). Hereafter, this quantity will be referred to as SSMsat. In this study, SSMsat consists of Geoland2 soil water index values with a characteristic time length of one day, denoted by SWI-001 (Kidd et al., 2013).

A surface-state flag which identifies frozen conditions, the presence of snow cover or temporary melting/water on the surface is provided. The product also includes a quality flag, indicating the availability of SSMsat measurements with an acceptable quality.

After screening, the remaining data were projected onto the $8 \mathrm{~km}$ resolution model grid by assigning each observation to all SAFRAN grid cells within $0.15^{\circ}$ and then considering the average of data assigned to each model grid. The model time series were compared with soil moisture data to determine their capability to represent the temporal dynamics at a grid scale. A good agreement between the SSMsat and the modelled SSM was found, despite anomalously low values of SSMsat produced in frozen surface conditions. These erroneous values are not adequately identified by the flags. This suggests that an additional frozen surface mask depending on model forecasts of frozen conditions has to be applied to the SSMsat data before being used in a data assimilation application. Similar to Draper et al. (2011), the screening procedure was extended to the use of two additional static masks in order to discard data in urban regions with a urban fraction greater than $15 \%$, and to remove data with a topographic flag representing mountainous regions with an altitude greater than $1500 \mathrm{~m}$.

\subsubsection{Satellite-derived LAI product}

The GEOV1 LAI product developed within the Geoland2 project is derived from the SPOT-VGT satellite observations. Hereafter, this quantity will be referred to as LAIsat. The LAIsat values are produced by a statistical algorithm, namely a neural network trained using two pre-existing products: the SPOT-VGT CYCLOPES V3.1 product (Baret et al., 2007) and the TERRA/ AQUA MODIS collection 5 product (Myneni et al., 2002). The product is provided globally at a spatial resolution of $1 \mathrm{~km}$ and a 10-day sampling time in a Plate Carrée projection. The LAIsat is close to the true LAI since the saturation effect affecting the CYCLOPES product for large LAI values corresponding to dense canopies was reduced by the MODIS contribution in the training process.
The retrieval methodology and detailed information about the product are described by Baret et al. (2013).

Camacho et al. (2013) performed a validation study by comparing the GEOV1 product with ground measurements and other reference satellite products. They concluded that the GEOV1 is a reliable product and has an important addedvalue regarding its two precursor products.

A quality check was performed using a number of quality flags provided by the LAIsat. The data are kept only if all the quality flags are set to 0 . The $1 \mathrm{~km}$ data are aggregated at the model grid at $8 \mathrm{~km}$ resolution if at least 32 grid points are present (more than half the maximum amount).

\subsection{Data assimilation}

The generic EKF calculation of the analysis increment $(\Delta \boldsymbol{x})$ at time when an observation is available is given by

$\Delta \boldsymbol{x}=\mathbf{K}\left[\boldsymbol{y}^{\mathrm{o}}-H(\boldsymbol{x})\right]$,

where $\boldsymbol{x}$ is the state vector and $\boldsymbol{y}^{0}$ is the observation vector. $\mathbf{K}$, which represents the Kalman gain, is calculated as in the following expression:

$\mathbf{K}=\mathbf{B} \mathbf{H}^{\top}\left[\mathbf{H} \mathbf{B} \mathbf{H}^{\top}+\mathbf{R}\right]^{-1}$.

Here $\mathbf{H}$ is the Jacobian matrix of the linearised observation operator $H$ and $\mathbf{H}^{\top}$ represents its transpose. The covariance matrices of the background (B) and observation $(\mathbf{R})$ errors are assumed to be diagonal. In the simplified version of the EKF used in this study, namely SEKF, the background covariance matrix $\mathbf{B}$ does not evolve with time.

As mentioned before, for the multi-patch version of the model, each model grid cell is divided into twelve patches, each with its own prognostic variables. The filter algorithm is designed to provide the analysis for each patch independently by using one grid-wise observation. Therefore, the model counterpart of the observation $\boldsymbol{y}=H(\boldsymbol{x})$ is assumed to be the average of the corresponding predicted observation for each patch $y_{\mathrm{p}}=H\left(x_{\mathrm{p}}\right)$ weighted with the fraction $\alpha_{\mathrm{p}}$ occupied by each patch $p$ :

$\boldsymbol{y}=\sum \alpha_{\mathrm{p}} H\left(x_{\mathrm{p}}\right)$.

Since the patches are considered independent and, consequentially, the simulated observation over the patch only depends upon the state vector over the same patch, the elements of the Jacobian matrix $\mathbf{H}_{\mathrm{p}}$ for each patch $p$ are

$H_{\mathrm{p}}^{m n}=\frac{\partial y^{m}}{\partial x_{\mathrm{p}}^{n}}=\alpha_{\mathrm{p}} \frac{\partial y_{\mathrm{p}}^{m}}{\partial x_{\mathrm{p}}^{n}}$,

where the $m$ and $n$ indices hold for $m$ th and $n$th components of observation and state vector, respectively. The elements of $\mathbf{H}_{\mathrm{p}}$ are estimated using a finite difference approximation by 
perturbing individually each analysed variable with a small perturbation $\delta x_{\mathrm{p}}^{n}$ :

$\mathbf{H}_{\mathrm{p}}^{m n}=\alpha_{\mathrm{p}}\left[\frac{y_{\mathrm{p}}^{m}\left(\boldsymbol{x}+\delta x_{\mathrm{p}}^{n}\right)-y_{\mathrm{p}}^{m}(x)}{\delta x_{\mathrm{p}}^{n}}\right]$.

Following a previous study (Barbu et al., 2011), the size of perturbations was set at $10^{-4} \times\left(w_{\mathrm{fc}}-w_{\text {wilt }}\right)$ for soil moisture and at $10^{-3}$ for LAI as they were proved to lead to an acceptable linearisation of the Jacobian. $w_{\mathrm{fc}}$ and $w_{\text {wilt }}$ represent the volumetric field capacity and the wilting point, respectively.

The Kalman gain is computed for each patch according to Eq. (3). A new value that represents the analysis for each patch $p$, denoted by $x_{\mathrm{p}}^{\mathrm{a}}$, is obtained by adding the analysis increment to the background. Through the Kalman gain, the Jacobian elements corresponding to different patches represent key factors controlling the analysis among patches. In this way, via the Jacobians, the corrections depend upon soil texture, vegetation cover and plant functional types. Finally, the updated variable $\boldsymbol{x}^{\mathrm{a}}$ is aggregated from the weighted contribution of each patch over the grid in the following way:

$\boldsymbol{x}^{\mathrm{a}}=\sum \alpha_{\mathrm{p}} x_{\mathrm{p}}^{\mathrm{a}}$

Figure 1 illustrates an example of the multi-patch data assimilation scheme for a grid cell split into three patches. The aggregation and disaggregation arrows correspond to the calculation of the model counterparts of a grid-scale observation $\boldsymbol{y}^{\mathrm{o}}$ and to the extraction of the data information distributed among the patches.

\section{Description of the experimental design}

A number of steps are necessary before assimilating the remote sensing data: projection of satellite data onto the $8 \mathrm{~km}$ model grid, bias correction using a cumulative distribution function (CDF) matching technique applied to the ASCAT data and specifications of model and observation errors.

\subsection{State vector and resolution}

In this study, the vector of observations includes two elements: SSMsat and LAIsat at each grid cell. The control state vector for the analysis consists of two prognostic variables, root-zone soil moisture and LAI, each of which contains 12 values that correspond to the twelve patches. The surface soil moisture does not belong to the vector state, but it is a prognostic variable in the ISBA-A-gs LSM.

The root-zone soil moisture is of great relevance to this study, as it governs the plant response to drought. Moreover, the Kalman filter is particularly useful for correcting the system variables with a slow temporal evolution, such as LAI and WG2. Due to the small capacity of the surface soil water

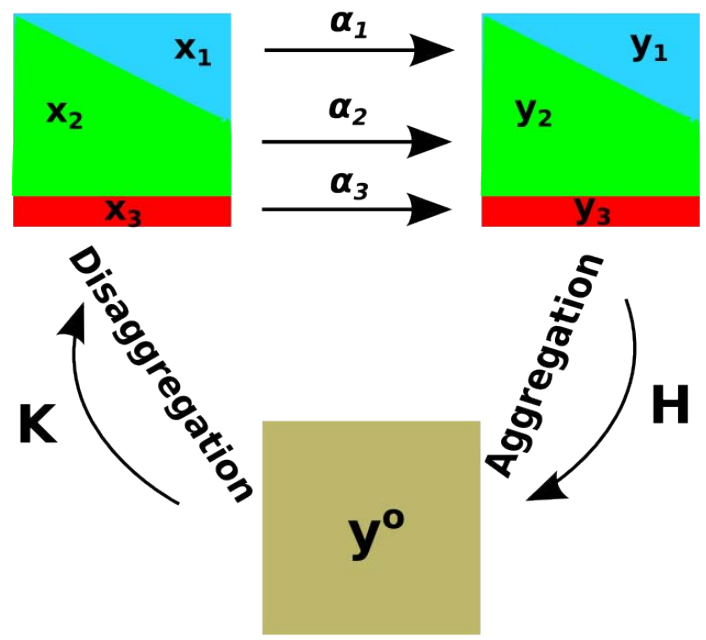

Fig. 1. The multi-patch data assimilation design for a grid cell split into three patches $p$ each having their variables $x_{\mathrm{p}}$. The predicted observations $y_{\mathrm{p}}$ are weighted with their fraction denoted by $\alpha_{\mathrm{p}}$, where $p \in 1,2,3$. $y^{0}$ represents the grid-scale observation. The observation operator $\mathbf{H}$ aggregates the predicted observations at the grid scale (Eq. 4). The data information is distributed among the patches via the Kalman gain $\mathbf{K}$ (Eq. 2).

reservoir, the SSM is rapidly influenced by the atmospheric forcing and by the capillarity rises from the deep reservoir. Therefore, a dedicated initialisation of the SSM is less important than that of WG2 associated with soil depths up to $2.5 \mathrm{~m}$. Following a recommendation of Draper et al. (2009), the SSM prognostic variable was excluded from the control vector in order to reduce the number of linearisations of the Jacobian. The modelled SSM is used to calculate the innovation and is linked to the control variable WG2 via the prognostic equations of the ISBA scheme. The SSM variable is indirectly corrected through the changes made by the assimilation in the deep reservoir.

The model simulations without data assimilation (prior) start in January 2007. The year 2007 is considered to be a spin-up period for the model run in order to obtain an equilibrium state. Then, the assimilation experiment starts on $1 \mathrm{Jan}-$ uary 2008 and lasts until 31 December 2011. The SEKF assimilates available observations every $24 \mathrm{~h}$ at 09:00 UTC by analysing the initial state via the information provided by an observation at the end of the assimilation window. The SSMsat observations are converted into volumetric water content (see Sect. 3.2) and assumed to be the observation equivalent of the SSMmod. Possible mismatch between observed and modelled quantities are accounted for in a bias correction scheme described in the next section. Concerning LAI, the satellite-derived product is considered to be the observation equivalent of the simulated LAI. The LAIsat is assimilated at the provided temporal resolution of 10 days.

The LDAS products (LAI, root-zone soil moisture, water, carbon and energy fluxes) are provided across the domain of 

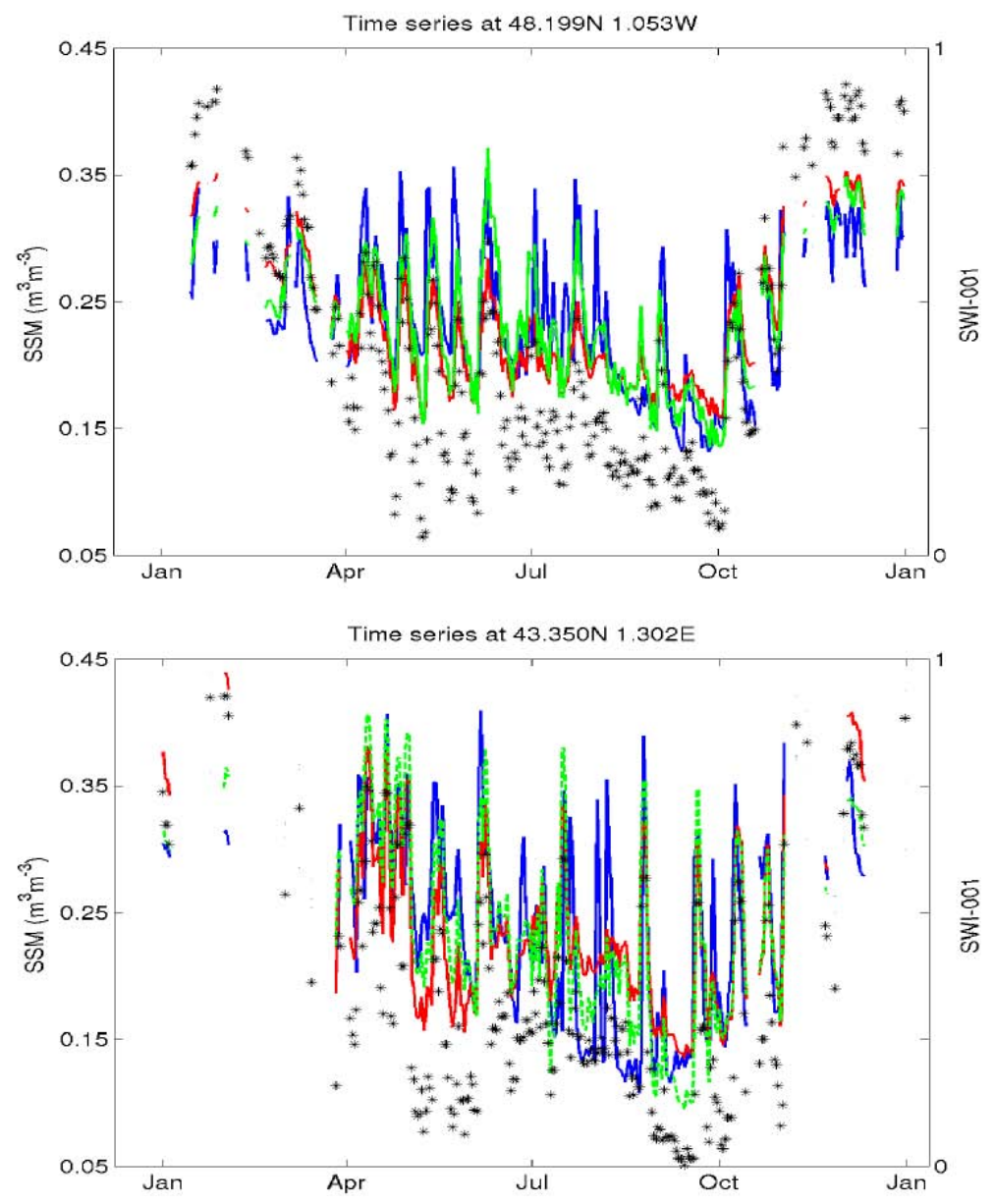

Fig. 2. Surface soil moisture evolutions for 2009 at a location in the north-east (top panel) and a location in the south-west (bottom panel) of France for model (blue), ASCAT CDF rescaled (red) and ASCAT seasonal CDF rescaled (green) observations. SWI-001 observations ranging between 0 and 1 are depicted by black stars.

France, which is divided into 8602 grid cells, each with $8 \mathrm{~km}$ resolution (Habets et al., 2008) at the temporal resolution of one day for the state variables LAI and soil moisture and as cumulated daily outputs for the fluxes. Hereafter, the analysed variables will be referred to as posterior, in contrast to the modelled variables referred to as prior.

\subsection{Rescaling and bias correction}

Prior to assimilation, the SSMsat product has to be transformed into model equivalent volumetric SSM. The discrepancies between the model simulations and the satellite observations are addressed as part of the data assimilation system. The SSMsat data are rescaled by matching their CDF to that of SSMmod. The approach described in Scipal et al. (2008) permits correcting for the differences in the first two moments (mean and variance) of the distribution and can be viewed as a linear transformation. The two parameters of the linear relationship, the intercept $a$ and the slope $b$, vary spatially, but are constant in time: $a=\bar{\theta}_{\mathrm{m}}-b \times \bar{\theta}_{\mathrm{o}}$,

$b=\frac{\sigma_{\mathrm{m}}}{\sigma_{\mathrm{o}}}$,

where $\bar{\theta}_{\mathrm{m}}$ and $\bar{\theta}_{\mathrm{o}}$ stand for the means of model and observation, respectively, while $\sigma_{\mathrm{m}}$ and $\sigma_{\mathrm{o}}$ represent the standard deviation errors for model and observations, respectively. Scipal et al. (2008) noted that the use of a linear transformation produces the bias-free observations (with respect to the model) for the entire considered period, but systematic differences related to seasonal or inter-annual variations in bias may remain uncorrected. The importance of accounting for seasonal corrections in the CDF matching was discussed in regards to the AMSR-E (Advanced Microwave Scanning Radiometer) SSM data and the SSM provided by the NWP system ALADIN of Météo-France by Draper et al. (2009).

Therefore, we have derived the $a$ and $b$ CDF matching parameters on a seasonal basis by using a three-month moving window from 2008 to 2011. The CDF matching moments are computed based on (1) screened observations with the 
quality flag provided by the SSMsat and additional aforementioned masks for altitude and urban fractions, and (2) SSMmod values for simulated soil temperatures above $0{ }^{\circ} \mathrm{C}$.

In Fig. 2 the model simulations were compared with the two CDF rescaled ASCAT time series (without seasonal corrections and with seasonal corrections) to determine their ability to represent the temporal dynamics at two locations, one in the north-east $\left(48.199^{\circ} \mathrm{N}, 1.053^{\circ} \mathrm{W}\right)$ and one in the south-west $\left(43.350^{\circ} \mathrm{N}, 1.302^{\circ} \mathrm{E}\right)$ of France. For both locations, the CDF matching with seasonal correction improves the temporal correlations between the data and the model in comparison with the approach without seasonal corrections from 0.72 to 0.79 (location in the north-east) and from 0.70 to 0.79 (location in the south-west). In addition, the seasonal bias correction reduces the standard deviation of the bias by $0.01 \mathrm{~m}^{3} \mathrm{~m}^{-3}$ for both locations.

One can notice low SSMsat values in May, especially in northern France as illustrated in Fig. 2 at local scale. Figure 3 shows that this characteristic is widespread in northern France. In the latter figure, the date of the annual minimum of SSMmod and of SSMsat as rescaled with the two CDF matching approaches are illustrated for the year 2009. The model simulates a minimum occurring in the summer period (after Day of Year - DOY - 200) across almost the full domain, with a few exceptions in the eastern part of France where the minimum is found around DOY 150 (left panel). The SSMsat minimum value is reached in May (before DOY150) over the northern and central regions (middle panel). This characteristic of ASCAT data is persistent over the entire $4 \mathrm{yr}$ period. Using a seasonal CDF matching approach helps to adjust the date of the minimum SSMsat to that of SSMmod as is illustrated in the right panel of Fig. 3.

\subsection{Background and observation errors}

For simulated root-zone soil moisture, a mean volumetric standard deviation (std) error of $0.02 \mathrm{~m}^{3} \mathrm{~m}^{-3}$ was chosen, as suggested by several authors (Mahfouf et al., 2009; Draper et al., 2011; Barbu et al., 2011). In this experiment, the observational error is set to $0.05 \mathrm{~m}^{3} \mathrm{~m}^{-3}$ according to the median value of SSMsat ASCAT data error estimates. This value is consistent with errors typically expected for remotely sensed soil moisture (de Jeu et al., 2008; Draper et al., 2011).

As in to Mahfouf et al. (2010) and Dharssi et al. (2011), a background quality control is performed in order to reject SSMsat converted to volumetric soil moisture that are too far from the model first guess. By assuming that the observation error is equal to SSMmod error, the data are discarded if the innovations (differences between observations and background) are larger than $0.21 \mathrm{~m}^{3} \mathrm{~m}^{-3}$ (i.e. three times the square root of the sum of the observation and background variances).

Concerning LAI, Barbu et al. (2011) estimated in situ LAI observation errors for grassland in a previous study. Their results are difficult to extend to satellite-based LAI uncertainties at the scale of France. In a recent study, Fang et al. (2013) estimated the average of the theoretical uncertainties of the GEOV1 product at the global scale. The theoretical uncertainties are related to the input data and retrieval processes, and resemble random errors. Fang et al. (2013) reported a std error value of $0.24 \mathrm{~m}^{2} \mathrm{~m}^{-2}$. In this study, the std errors of LAIsat is increased up to 0.3 in order to account for the additional uncertainties related to the aggregation procedure from 1 to $8 \mathrm{~km}$ resolution.

Generally, the start and the end of the growing season are considered to be better represented by the satellite products (Jarlan et al., 2008; Brut et al., 2009; Szczypta et al., 2012). Preliminary tests showed that to ensure that the phenology derived from LAIsat is preserved, the observational errors have to be smaller than the model errors: the std errors of the modelled LAI is set to $0.6 \mathrm{~m}^{2} \mathrm{~m}^{-2}$. It has been checked that the observation and model error specifications are consistent with innovation statistics.

\subsection{Jacobian terms}

The Jacobian of the observation operator $(\mathbf{H})$ required to calculate the Kalman gain (Eq. 3) and the increments (Eq. 2) was generically described in Sect. 2.3. Explicitly, the Jacobian terms are written as

$\mathbf{H}=\left[\begin{array}{ll}\frac{\partial \operatorname{SSM}(t)}{\partial \operatorname{WG} 2\left(t_{0}\right)} & \frac{\partial \operatorname{SSM}(t)}{\partial \mathrm{LAI}\left(t_{0}\right)} \\ \frac{\partial \operatorname{LAI}(t)}{\partial \operatorname{WG} 2\left(t_{0}\right)} & \frac{\partial \operatorname{LAI}(t)}{\partial \operatorname{LAI}\left(t_{0}\right)}\end{array}\right]$.

The Jacobian $\frac{\partial \operatorname{SSM}(t)}{\partial \mathrm{WG} 2\left(t_{0}\right)}$ was estimated in finite differences by Draper et al. (2009). Mahfouf et al. (2010) defined an analytical formulation of this term, which represents the sensitivity of SSM to changes in WG2. The effect of different soil moisture responses in the bare soil and in the vegetated ground is taken into account through this Jacobian term. Several authors (Calvet and Noilhan, 2000; Draper et al., 2009) demonstrated that its behaviour over bare soil is significantly different from its behaviour over a vegetated surface. During a rainfall event this sensitivity is strongly reduced, and the SSM observations are not informative about the root zone soil moisture content. In the absence of precipitation, the influence of WG2 on SSM is mainly determined by the evapotranspiration processes via a mechanism described by Draper et al. (2009). The Jacobian element has higher values over vegetated areas due to an increased coupling between the two layers in the ISBA force-restore scheme. Conversely, over bare soil a reduced sensitivity of SSM to WG2 is noticed at daytime, when high evaporation rates occur.

Concerning the second diagonal element of the Jacobian matrix, $\frac{\partial \operatorname{LAI}(t)}{\partial \operatorname{LAI}\left(t_{0}\right)}$, Rüdiger et al. (2010) noted that three types of Jacobian values can be identified: (1) a value identical to zero, (2) a close-to-maximal value equal to the fraction occupied by the plant functional type, and (3) a fraction of maximal value decreasing during the growing phase of the vegetation. This behaviour is common to all patches. The zero 

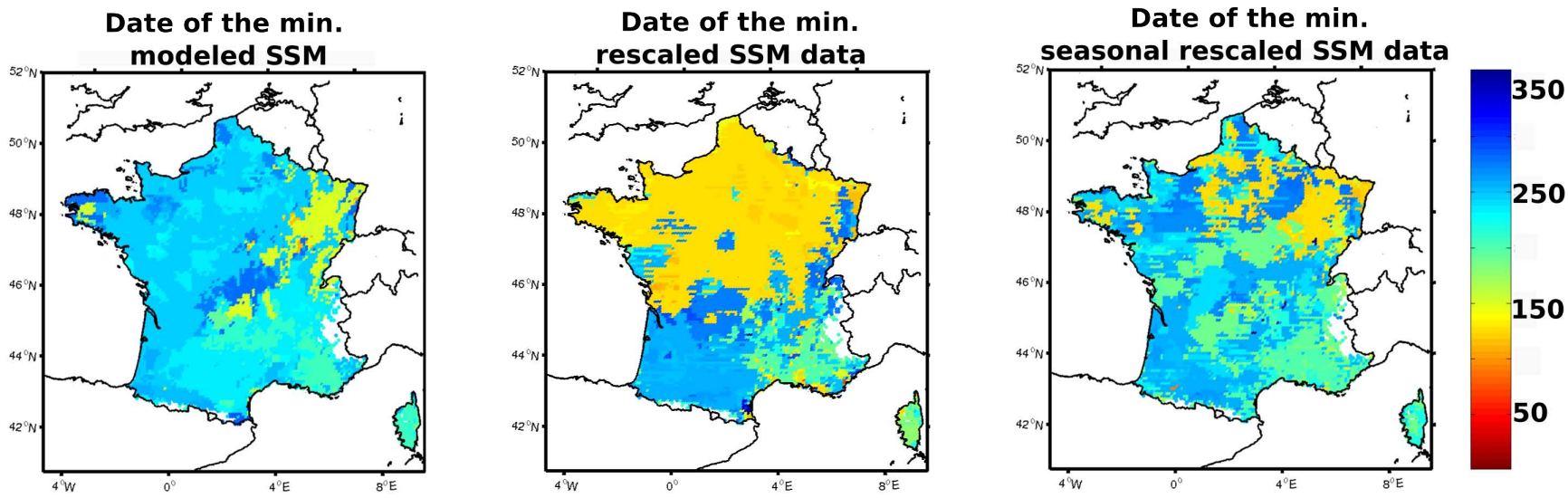

Fig. 3. Date of the lowest SSMmod values (left panel), CDF rescaled SSMsat (middle panel) and seasonal CDF rescaled SSMsat (right panel) for the year 2009 across the domain of France. The colour bar represents the days of the year.

Jacobian value occurs when the LAI declines down to its minimal value in winter due to environmental conditions and also during drought periods. This non-informative Jacobian value has a larger frequency of occurrence in drought periods for the herbaceous vegetation types, as they are more sensitive than forests to the water stress.

The off-diagonal elements of the Jacobian matrix $\mathbf{H}$ reflect how the link between soil moisture and vegetation variables is directly exploited by the multivariate analysis. The joint assimilation is effective when the values of these Jacobian terms are non-zero. This means that the system is able to provide information from observations to those model variables that are connected to the data.

The off-diagonal element $\frac{\partial \mathrm{LAI}(t)}{\partial \mathrm{WG} 2\left(t_{0}\right)}$ represents the sensitivity of LAI to water perturbations in the rooting layer. Its behaviour will be analysed in Sect. 4.1. The Jacobian $\frac{\partial \operatorname{SSM}(t)}{\partial \operatorname{LAI}\left(t_{0}\right)}$ represents the sensitivity of SSM to LAI. Its small values indicate that LAI does not substantially influence SSM (not shown).

\section{Results}

\subsection{Jacobian term $\frac{\partial \operatorname{LAI}(t)}{\partial \mathrm{WG} 2\left(t_{0}\right)}$}

Time series of the Jacobian term $\frac{\partial \mathrm{LAI}(t)}{\partial \mathrm{WG} 2\left(t_{0}\right)}$ for the year 2009 at one location $\left(43.35^{\circ} \mathrm{N}, 1.30^{\circ} \mathrm{E}\right)$ in south-western France are illustrated in Fig. 4. The three main vegetated patches are present in the grid cell: C3 crops (48\%) depicted in blue, grassland (19\%) in green, and deciduous forest (9\%) in red. Bare soil represents $14 \%$. The black curve represents the normalised soil moisture (NWG2) corresponding to the C3 crop patch. The NWG2 is defined as

$\mathrm{NWG} 2=\frac{\mathrm{WG} 2-w_{\text {wilt }}}{w_{\mathrm{fc}}-w_{\text {wilt }}}$.

The dimensionless values of NWG2 are larger than 1 when the soil moisture content exceeds the volumetric field

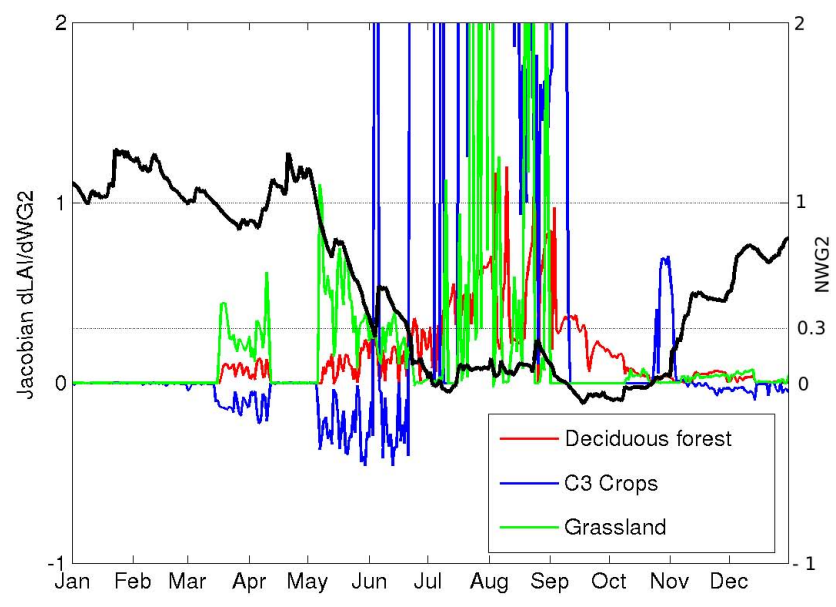

Fig. 4. Time series of daily Jacobian values for the majority patches (deciduous forest, $\mathrm{C} 3$ crops and grassland) at a location $\left(43.35^{\circ} \mathrm{N}\right.$, $\left.1.30^{\circ} \mathrm{E}\right)$ in south-west of France for 2009. The simulated normalised soil moisture (NWG2) for the C 3 crop patch is represented in black.

capacity and negative when the soil moisture content is below the wilting point, meaning that the root water uptake has stopped.

As illustrated in Fig. 4, the Jacobian term $\frac{\partial \mathrm{LAI}(t)}{\partial \mathrm{WG} 2\left(t_{0}\right)}$ has generally positive values, since an increase in water content directly enhances photosynthesis and plant growth (Barbu et al., 2011). This behaviour is common to all patches with one noticeable exception: the occurrence of negative values for the C3 crop patch (blue curve in Fig. 4) in spring and early summer. For normalised soil moisture values ranging between a given critical limit of 0.3 and 1 , a moderate water stress was defined in the ISBA-A-gs scheme. In these conditions, a drought-avoiding strategy which characterises the crop vegetation takes place. A decrease in soil moisture is characterised by an increase in the water-use efficiency, 

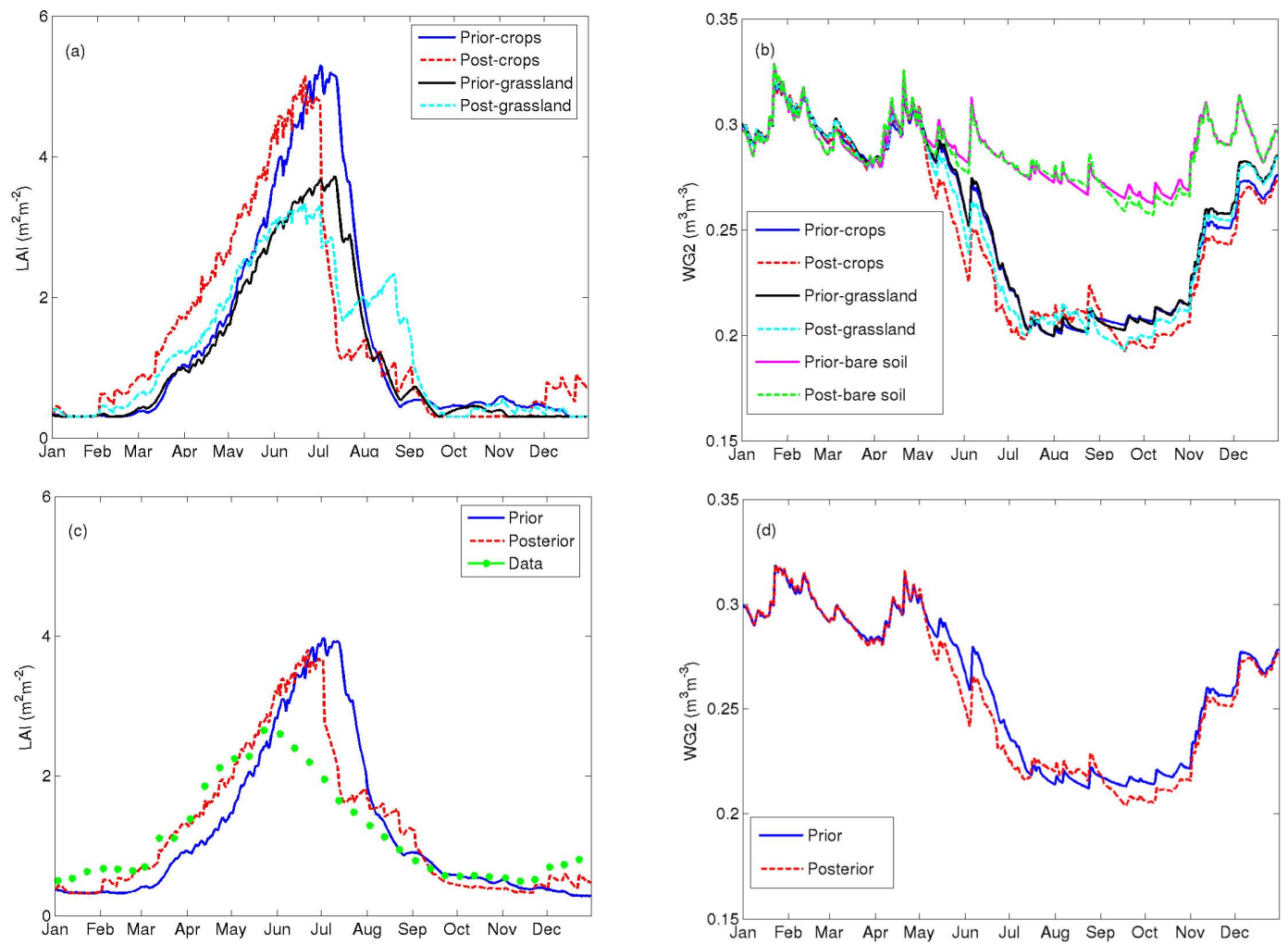

Fig. 5. Time series of prior and posterior LAI in $\mathrm{m}^{2} \mathrm{~m}^{-2}$ (left panels) and volumetric root-zone soil moisture (right panels) per patches (top panels) and per grid cell (bottom panels) at a location $\left(43.35^{\circ} \mathrm{N}, 1.30^{\circ} \mathrm{E}\right)$ for the year 2009 . The majority of patches are cropland $(48 \%)$, grassland $(19 \%)$ and bare soil $(14 \%)$. The LAI satellite data gathered at this location are depicted by stars.

which enhances photosynthesis. Therefore, between these limits, negative water perturbations can lead to an increase in photosynthesis and therefore to negative Jacobian values.

As shown in Fig. 4, during the senescence phase, large Jacobian values (above 1) correspond to advanced stages of water stress. When the normalised soil moisture approaches zero, small increases in WG2 cause large increases in biomass production, which reveals a specific non-linear behaviour of the ISBA-A-gs scheme. This behaviour is common to all patches. Null Jacobian values, indicating no sensitivity of LAI to soil moisture, occur when the water content is below the wilting point (September-October) or above the volumetric field capacity (January-February). In these cases the plant is not sensitive to water perturbations and therefore LAI observations are not informative about the water content.

\subsection{Impact of assimilation on LAI and WG2 at patch level}

Figure 5 shows the prior and posterior LAI and WG2 daily evolutions per patch (top panels) and aggregated at pixel level (bottom panels) at the same location $\left(43.35^{\circ} \mathrm{N}, 1.30^{\circ} \mathrm{E}\right)$ in south-western France for the year 2009. The root-zone soil moisture starts to decline in May and reaches a minimum in September (Fig. 5d), whereas LAI increases from March through May and remains high until July (Fig. 5c).

The LAI evolution between two assimilation steps for the two dominant vegetation types (crops and grassland) is rather similar. The LAI increments are distributed among the patches according to the fraction occupied by each patch in the model grid cell. In spring, the positive increments are larger for $\mathrm{C} 3$ crops since they represent the main vegetation type within the grid cell. In summer, in water-limited conditions, the temporal evolution of LAI per patch creates a more complex picture due to the combined effect of LAI and soil moisture analysis, and also, due to possible conflicting data information to be assimilated. This is illustrated in Fig. 5a and $b$. On the one hand, in June/July, in a moisture-limited regime (close to the wilting point), the Jacobian $\frac{\partial \mathrm{SSM}(t)}{\partial \mathrm{WG} 2\left(t_{0}\right)}$ has large positive values (strong non-linearities in the description of the water diffusion in the ISBA scheme) that generate large negative WG2 increments. In this way, the reduction in soil moisture content in June/July due to the soil moisture assimilation contributes to a more rapid decrease of LAI towards the low LAIsat values. Consequentially, simultaneously assimilating the two data streams results in a bias reduction in LAI. On the other hand, after this period, the SSMsat data are consistently above model values (see Fig. 2, 
bottom panel) and then the analysis accumulates positive increments in the root zone. This results in a slightly enhanced WG2 that allows a vegetation regrowth for both cropland and grassland (panels a and b). The vegetation regrowth is related to sufficient water availability only, as this behaviour is not confirmed by LAIsat observations. The assimilation of LAI draws the model trajectory back towards the lower observed LAI values by balancing between these two opposing tendencies in the data streams, as is clearly depicted in Fig. 5c at the grid scale.

As mentioned by Reichle (2008), a data assimilation system is able to join potentially redundant or conflicting data into a single best estimate. The occurrence of conflicting data in an assimilation system has been investigated for grasslands by Barbu et al. (2011) and also by Kato et al. (2013) in a local experiment conducted over a semi-arid woodland. Their conclusion was that the multivariate assimilation is a valuable method that permits the identification of biases in the observations and of shortcomings in the model parameterisation. In our case, such problems may occur in the period of vegetation senescence due to limitations in the model physics (uncertainty in the relation between soil moisture and photosynthesis activity) and in the assimilation scheme (bias correction of SSMsat via the CDF matching). Anyway, such limitations are more difficult to detect when only one set of observations is assimilated.

The WG2 value shows a consistent seasonality among the patches, presenting a higher dynamic range for vegetated areas than for bare soil in relation to the water uptake by the plants. During wintertime and early springtime, there are no significant differences between the vegetated patches and bare soil.

Finally, despite the spatial heterogeneity of a $8 \mathrm{~km}$ grid cell and the complex behaviour of each vegetation type at sub-pixel level, the assimilation is able to successfully exploit mixed information and create improved updated values aggregated at the grid scale.

\subsection{Impact of assimilation on LAI, WG2 and fluxes at grid level}

Before assimilation, LAIsat was compared with the model simulations over the domain of France. Figure 6 (top panel) presents the LAI time series for the model (referred to as prior), LAIsat data and assimilation (referred to as posterior) averages over France, respectively. The annual cycles are rather different from one year to another. In 2008 the model has the longest cycle and the highest LAI maximum, while the satellite data show the largest LAI maximum in 2009. In 2011 LAI has a different seasonal cycle. Unusually high temperatures and low amount of precipitation characterised the 2011 spring in France. In relation to these conditions, both LAIprior and LAIsat maximums are lower. A vegetation regrowth occurs in August 2011 after rainfall events.
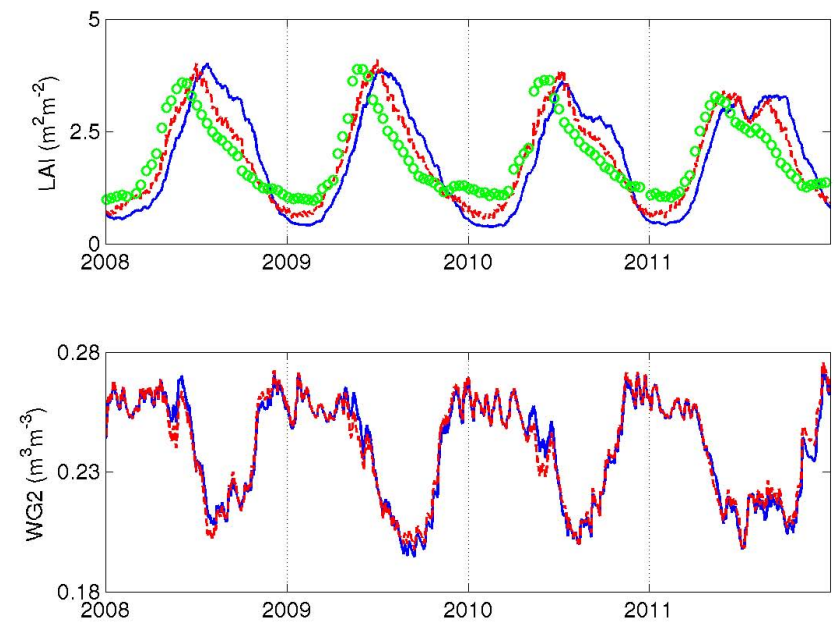

Fig. 6. Time series of prior (blue), observed (green) and posterior (red) LAI $\left(\mathrm{m}^{2} \mathrm{~m}^{-2}\right.$ ) (top panel) and prior (blue) and posterior (red) volumetric root-zone soil moisture (bottom panel) averaged over France from 2008 to 2011.

In a previous study, Lafont et al. (2012) noted systematic differences between the maximum LAI simulated by ISBAA-gs and the LAI derived from two remote sensing products (namely from CYCLOPES and MODIS over France) as well as in the timing of the phenological cycle. In this study, comparison between LAIprior and LAIsat reveals a good agreement in terms of amplitude and in terms of inter-annual variability. By contrast, the model simulations show a shifted phenology compared to the one observed by the satellite. Regarding the causes that determine the mismatch between the model and the data, one can mention the differences in LAI values at the beginning of the growing cycle, LAIsat having larger values in winter (up to $1 \mathrm{~m}^{2} \mathrm{~m}-2$ ) than LAIprior (around $0.5 \mathrm{~m}^{2} \mathrm{~m}^{-2}$ ). As a result, the start of the growing season tends to occur one month later in the model than in the observations. Similarly, the summertime senescence phase is delayed. The updated LAI shows a much better fit to the data over all the period. The averaged correlation coefficient between LAIsat and the simulated LAI values increases from 0.58 for the prior LAI to 0.88 for the posterior LAI. Figure 6 (bottom panel) shows also the volumetric WG2 time series for the model (referred to as prior) and for the assimilation (referred to as posterior) averages over France. One can notice that the longest dry period occurs in 2011. Generally the assimilation reduces the soil moisture content during the period of the vegetation growth (April-May) and increases the WG2 values at the end of the annual cycle.

Figure 7 illustrates the maps of monthly averaged prior LAI, LAIsat and posterior LAI over France. During wintertime and in the early spring, the low LAI values already noticed reveal a bias between the model and the data. The spatial maps of satellite observations show higher LAI over many regions (Brittany, Massif Central) from December to 

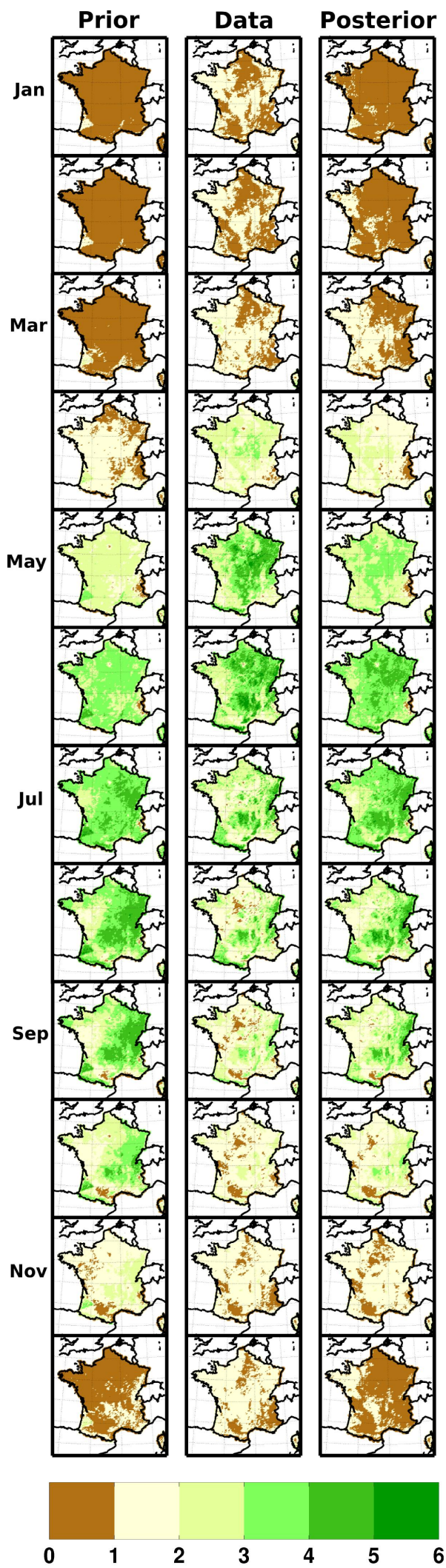

Fig. 7. Maps of monthly averages for prior (left panels), data (middle panels) and posterior (right panels) LAI over the period 20082011. The units are in $\mathrm{m}^{2} \mathrm{~m}^{-2}$.
March. The assimilation is able to maintain higher LAI values over these regions, except in January. In March and April, the data assimilation increases the LAI values. As a consequence, the delay in the leaf onset is reduced. The start of declining LAIsat values occurs in July and is located over the agricultural areas in northern and southern France, as well as in the Mediterranean zone where the soil water stress is more acute. In the model, the senescence occurs later, following the same regional patterns as observed by satellite, but with a tendency to maintain high values until October. The lack of a detailed representation of the farming practices in the model (e.g. crop rotation and winter vs. summer crops) is then compensated by the assimilation. The simulated seasonal LAI cycle across crop regions is shifted towards the LAIsat cycle.

To evaluate the performance of the assimilation system, the innovations (differences between observations and background) and the residuals (differences between observations and analysis) were examined for LAI only, since the simulated LAI variable was also the observed variable. Figure 8 illustrates the LAI monthly averages of innovations and residuals. One noticeable feature is the sign of the differences between LAIsat and LAIprior. In winter and spring, the simulated values are underestimated, while in rest of the period, corresponding to the senescence, they are overestimated. The assimilation tends to smooth out these differences, resulting in a less marked contrast between these two periods of the annual cycle with positive and negative increments of about the same magnitude. As expected, the residuals are smaller than the innovations.

The changes operated in the seasonal LAI and WG2 cycles by the LDAS impact the seasonal and annual simulations of carbon and water fluxes. Figure 9 shows the average annual cycle over France of the relative differences (in units of $\%$ ) between posterior and prior simulations with respect to prior simulations for LAI, WG2, evapotranspiration and GPP. The largest assimilation impact on LAI is obtained in early spring and ranges between +42.50 and $+89.8 \%$. Less marked LAI differences (between -20.6 and $-32.70 \%$ ) are noticed at the end of vegetation cycle. These relative differences in LAI are translated in terms of GPP relative differences with similar magnitude and seasonal behaviour. The impact of LAI updates on carbon fluxes is illustrated by the increased photosynthetic activity related to higher LAI values in the growing season (April) due to data assimilation corrections. In the same manner, the decrease in the $\mathrm{CO}_{2}$ uptake during the senescence phase (August-September), when compared to the prior simulation, is related to lower LAI values. The changes in WG2 range between $-3.33 \%$ (May 2010) and 2.65\% (November 2011). The largest negative differences occur in May for all years. Positive relative differences are obtained in the end of the summer and during autumn. The impact of the assimilation on evapotranspiration is less marked (the relative difference ranges between +20.4 and $-10.3 \%$ ). In March and April the acceleration of the vegetation growth by data assimilation tends to increase 


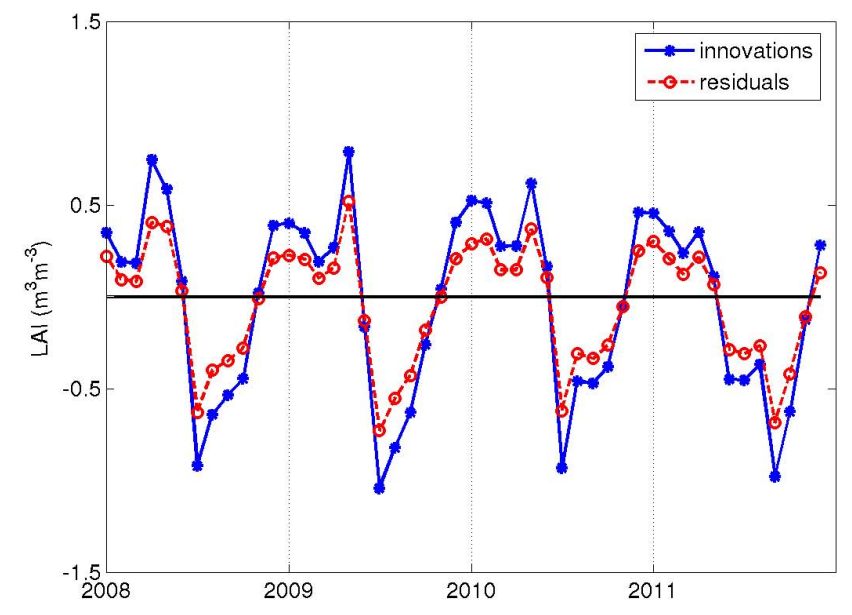

Fig. 8. Monthly evolution of LAI innovations (in blue) and residuals (in red) in $\mathrm{m}^{2} \mathrm{~m}^{-2}$ units averaged over France.

plant transpiration - for example up to $17.2 \%$ in March 2011 and $20.4 \%$ in April 2010. In the latter case, the augmentation of ET corresponds to an increased LAI of $61.3 \%$.

The LAI is an important driving variable for carbon and water fluxes, but the soil moisture has also a critical influence on the fluxes. Figure 10 shows the average monthly maps of LAI and WG2 increments and of the differences between the posterior and prior water fluxes (evapotranspiration and drainage). During wintertime (from December to February) the increments in WG2 present low values due to the reduced sensitivity of the Jacobian values during the widespread rainy episodes in this period. As the updated WG2 exceeds a maximum threshold (field capacity), the excess water is drained out. In these conditions, small variations in WG2 may lead to large variations in total runoff. This impacts the drainage in winter within approximately $10 \%$. In the same period, the positive LAI increments help the model to adjust its minimum values to those of LAIsat. Due to the limited energy regime and the low vegetation activity, the evapotranspiration is not sensitive to soil moisture and LAI changes.

In November, positive increments in WG2 are accumulated across the northern and central parts of France. The analysis increments are translated into drainage rather than into other components of the water budget, as already noticed by Draper et al. (2011). This results in an important drainage flux in December. The process is amplified by the lower evapotranspiration rate due to lower incoming energy, as well as by the advanced phase of the senescence.

In March and April, positive increments in both LAI and WG2 lead to an augmentation of water fluxes. By contrast, negative soil moisture corrections are applied in May across the domain. This is due to the combined effects of the LAI and the soil moisture analysis. ASCAT is the main contributor to the changes in WG2 (by $73 \%$ on average), since, in general, the assimilation of SSM impacts WG2 more than the assimilation of LAI. Also, the assimilation of SSM is more frequent than the assimilation of LAI. This results in a reduction of WG2. In addition, the assimilation of LAI data into the model increases the vegetation biomass via increased LAI values and, consequently, the plant transpiration.

In June the assimilation starts to impact negatively on the LAI values, but shows a large increase in soil moisture content. As a consequence, the vegetation is less stressed and a positive rate of transpiration is maintained, with a few exceptions in Brittany and in the Mediterranean region. In July and August the maps of evapotranspiration fluxes show more heterogeneous patterns. One can notice a tendency towards reduced ET fluxes over the large agricultural area in northern France. In August, positive soil moisture increments across the western part of France are sufficient to maintain a higher rate of evapotranspiration.

Under dry conditions, evaporation is highly sensitive to soil moisture, but with limited values and variations (Seneviratne et al., 2010). This regime is relevant over the Mediterranean area in summer. The negative soil moisture increments show a decrease in soil moisture content that stresses vegetation, and evapotranspiration is thus reduced.

\section{Discussion}

\subsection{Impact of assimilation on vegetation response to drought}

Drought monitoring is a research field of major interest. The importance of the complex ecological and hydrological responses of ecosystems to drought has been highlighted in a number of studies (van der Molen et al., 2011; Hirschi et al., 2011; Ciais et al., 2005). Our interest is focused on the shortterm responses of vegetation to agricultural drought.

As mentioned before, the spring 2011 was characterised by the most severe drought recorded in the last $50 \mathrm{yr}$ in France. According to Météo-France (http://www. meteofrance.com/climat/france), spring rainfall deficits of more than half of the long-term mean were associated with temperatures up to $2.5^{\circ} \mathrm{C}$ above normal, more than in 2007 $\left(+2.1^{\circ} \mathrm{C}\right)$ and in $2003\left(+1.8^{\circ} \mathrm{C}\right)$. The deficit of precipitation was generally more marked on the north-western two-thirds of the country. The average soil moisture level recorded in May was similar to what could normally be found in July or August. Drought conditions were reduced in July in relation to precipitation $30 \%$ above normal at the country level.

In contrast to the drought of 2003 that occurred in the beginning of the senescence phase of vegetation, the drought in spring 2011 had an important impact on the vegetation development in the peak of its growing phase, resulting in a diminution of crop productivity (Sepulcre et al., 2012). As a result, low maximum LAI values are simulated by the model as well as observed by satellite. While the two sources of information agree on the maximum and mean values of LAI (Fig. 6), they disagree on the timing of the effects caused by 

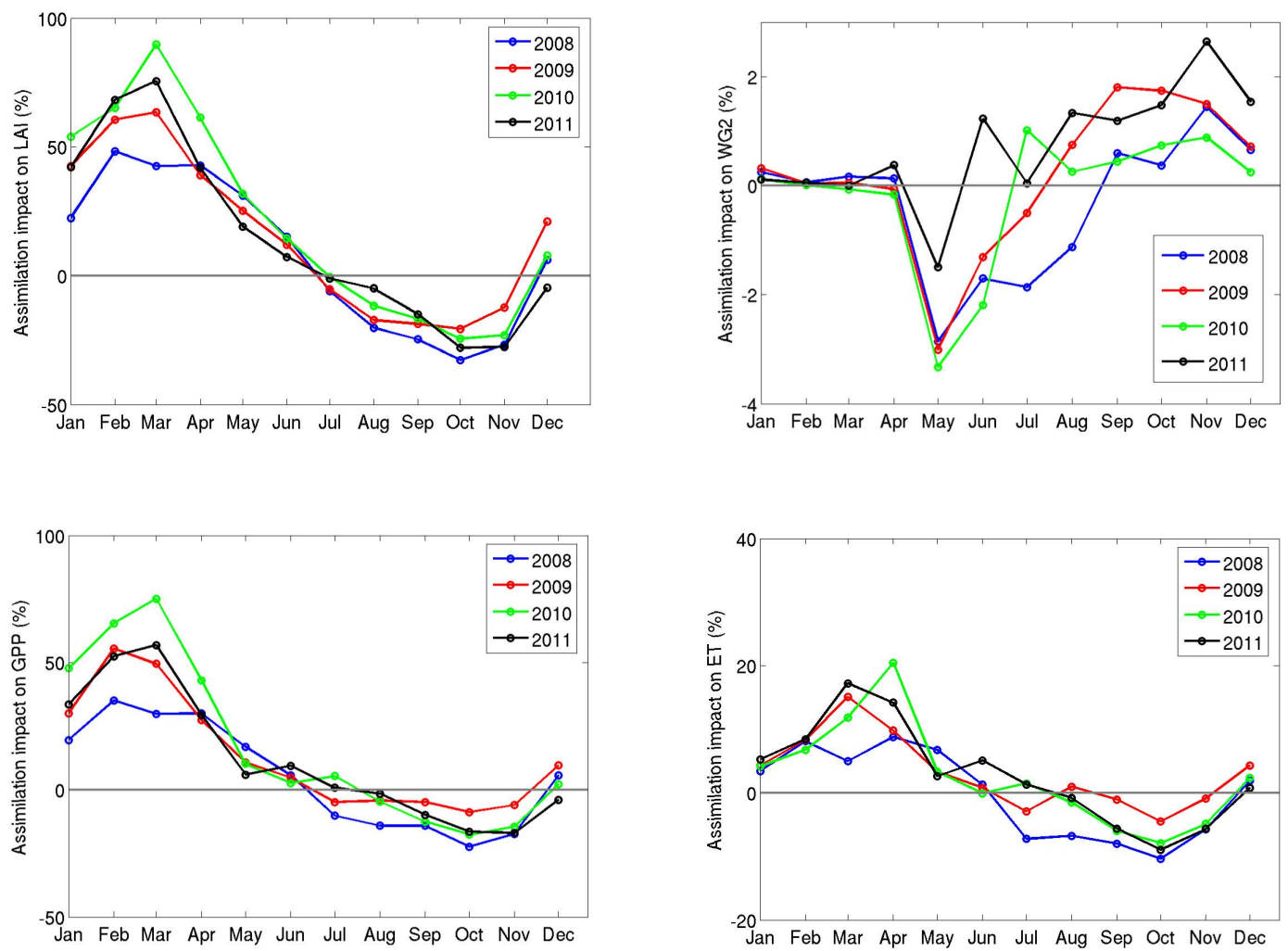

Fig. 9. Assimilation impact in terms of monthly relative differences (in \%) between the posterior and the prior spatial averages for LAI (top left panel), soil moisture WG2 (top right panel), GPP (bottom left panel) and ET (bottom right panel) fluxes.

the drought. The remote-sensing observations show an earlier response to the occurrence of the drought.

Figure 11 shows the change rate of LAI calculated over 10-day periods and highlights the changes in the strength and duration in the vegetation development. Unusually low LAIsat values are detected in April over the western part of France, while the model does not detect the negative changes before the end of May.

On the one hand, the most severe decreases in LAIsat values are observed in the middle and the end of June over large regions, while in the first 20-day period in July the evolution of LAI is much steadier. On the other hand, the model shows similarly pronounced negatives changes, but during the first 20 days of July, and a steadier evolution in the last 10 days of July.

In the LDAS configuration, the analysis is able to produce an earlier decline in LAI values. The temporal shift in the vegetation response to the severe water stress is about 20 days earlier in the western part of France and about 10 days earlier in the central parts of the domain. The negative trend in the LAI evolution extends to the first period of July, without reaching a steady state. At the end of July, the changes in the posterior LAI are close to the LAIsat with a clear positive trend in the south-western and central regions of France. The model response to the precipitation that occurs in the second period of July is enhanced by the assimilation allowing a faster regrowth of the vegetation.

Figure 12 shows the change rate of prior and posterior volumetric WG2 calculated over 10-day periods from March to July. In April and May one notices a constant decrease rate in soil moisture values at the country scale. This behaviour is maintained in the beginning of June for the northern half of the territory. During the last two 10-day periods of July the WG2 values increase. The assimilation enhances this tendency at the end of July.

A significant reduction of modelled photosynthesis and $\mathrm{CO}_{2}$ fluxes is experienced in June and July 2011. For example, in June, the mean reduction in GPP and NEE is of 31 and $45 \%$ respectively, compared to the flux values averaged over the same month from 2008 to 2010 . This period also coincides with a decline of evapotranspiration in response to a pronounced water deficit. Despite a temperature increase above average that tends to enhance the photosynthetic activity, the water stress has an adverse effect on GPP.

By contrast, on an annual basis, the GPP and NEE fluxes at the scale of France show a slight increase (of 2.5 and $2 \%$, respectively) compared to the annual averages calculated for the period 2008-2010. This can be explained by an acceleration of the vegetation development at the beginning of the growing phase due to warmer-than-normal temperatures, as 
LAl increments $\left(\mathrm{m}^{2} / \mathrm{m}^{2}\right)$
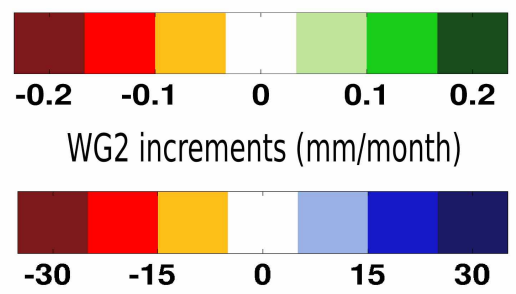

LAI incr WG2 incr

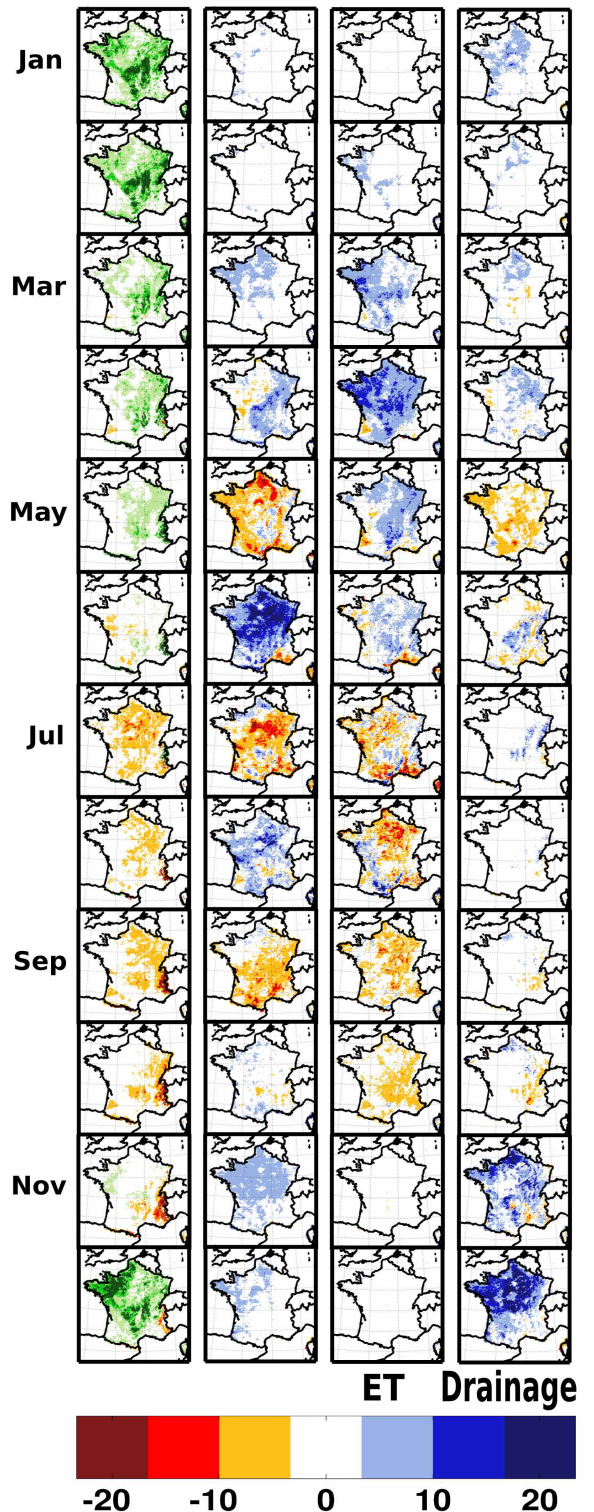

ET and drainage differences ( $\mathrm{mm} /$ month)

Fig. 10. Monthly maps of LAI (first column), soil moisture (second column) increments and the differences (posterior minus prior) for ET and drainage fluxes (third and fourth columns, respectively) averaged over 2008-2011. The units are in $\mathrm{m}^{2} \mathrm{~m}^{-2}$ for LAI and in $\mathrm{mm}$ per month for water fluxes. well as by an extended season of active biomass production after summer rainfalls. Every month in 2011 was warmer than normal, with one noticeable exception in July. The large reduction of the GPP fluxes in June and July is compensated for by the positive impact of higher-than-average monthly temperatures in early spring and in autumn and a wetter-thanaverage summer. The LDAS does not change this tendency.

Figure 13 illustrates the change rate in the photosynthesis fluxes from one 10-day period to the next one. One can notice similar positive changes in the GPP fluxes in March and the first 10 days of April, corresponding to the positive changes in LAI. In the last two-thirds of April, negative changes appear in the south-eastern regions and extend to the western and the central parts of France after assimilation, despite positive changes detected in LAI. From May to July the changes in GPP induced by analysis follow almost the same patterns as in the model, but with differences in intensity. For example, in the first two-thirds of May, an increased reduction of photosynthetic activity in the western and in the central part of France is produced by the LDAS.

\subsection{Verification using SMOSMANIA database}

The scarcity of soil moisture and LAI in situ data limits the possibility of an independent validation of the assimilation results. In addition, point measurements are not necessarily representative of a coarser pixel scale, and thus are difficult to interpret when compared to model results.

Despite the above limitation, the results of the assimilation were evaluated against the 12 SMOSMANIA (Soil Moisture Observing System-Meteorological Automatic Network Integrated Application) sites of Météo-France located in the south-west of France (Calvet et al., 2007). All of the stations are located in natural fallow.

The volumetric soil moisture values are derived from capacitance probes ThetaProbe ML2X of Delta-T Devices. Soil moisture observations are gathered at depths of 5, 10, 20, $30 \mathrm{~cm}$ every $12 \mathrm{~min}$. For this verification only measurements made at $30 \mathrm{~cm}$ were used.

Since the observations are representative only of the first $30 \mathrm{~cm}$ of soil, the impact of the analysis on WG2 is investigated by computing the absolute correlation and anomaly correlation between the simulated and observed soil moisture. The statistics are calculated at each station over the entire period. The measurements are compared to the simulated WG2 corresponding to the grassland patch. The anomaly time series are calculated by using a 30-day moving window as described in Draper et al. (2011). The significance level of correlations ( $p$ values $<0.01$ ) was obtained for all stations. Soil moisture is in a good agreement with in situ measurements at the SMOSMANIA stations, with correlations higher than 0.7 , which indicates that the model captures already the soil moisture variability well. Moreover, the correlation coefficient for two stations is greater than 0.9. Generally, the correlations values do not vary significantly, showing that the 


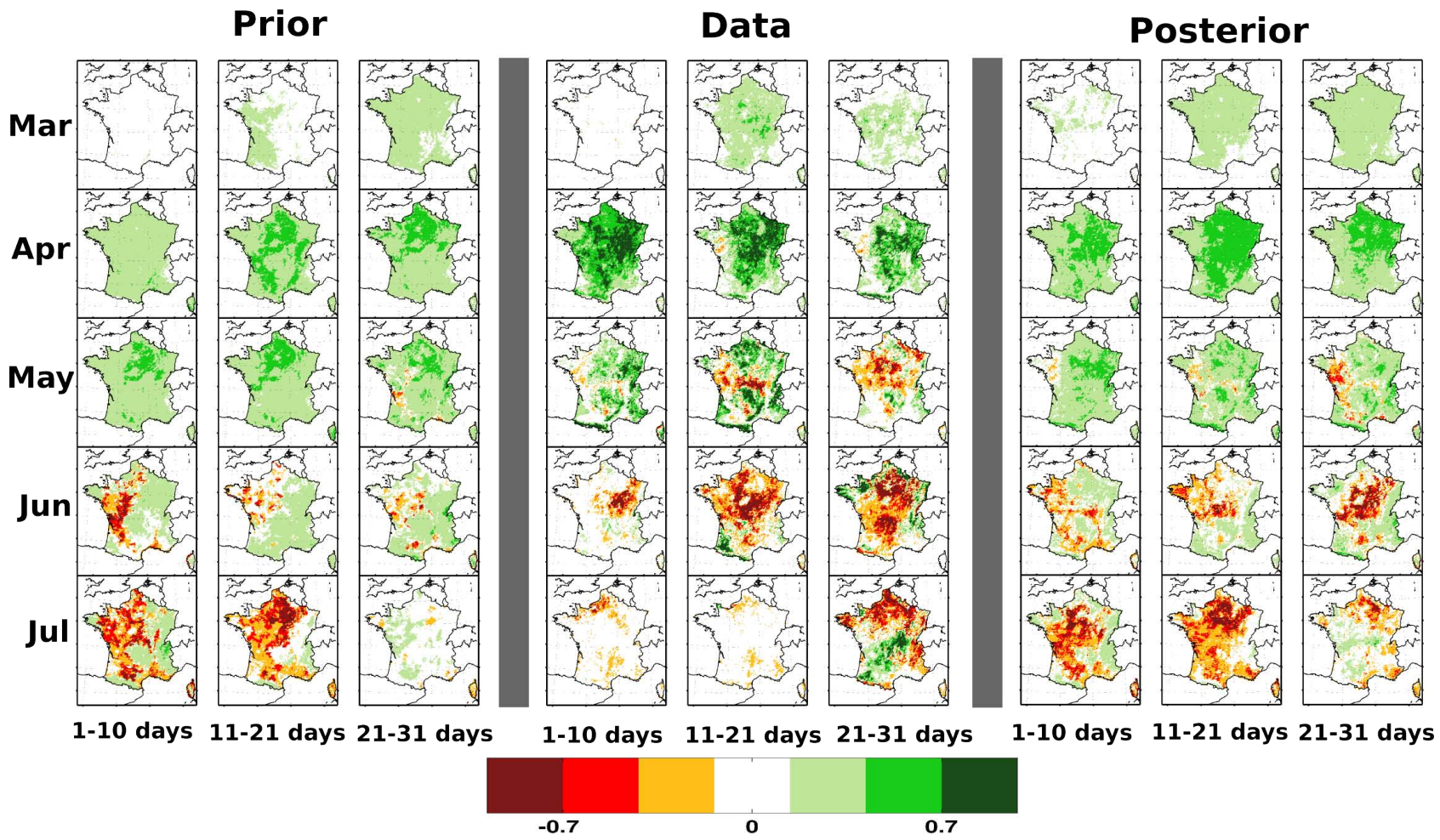

Fig. 11. Change rate calculated over a 10-day period for prior, observed and posterior LAI from March to July 2011. The units are in $\mathrm{m}^{2} \mathrm{~m}^{-2}$.

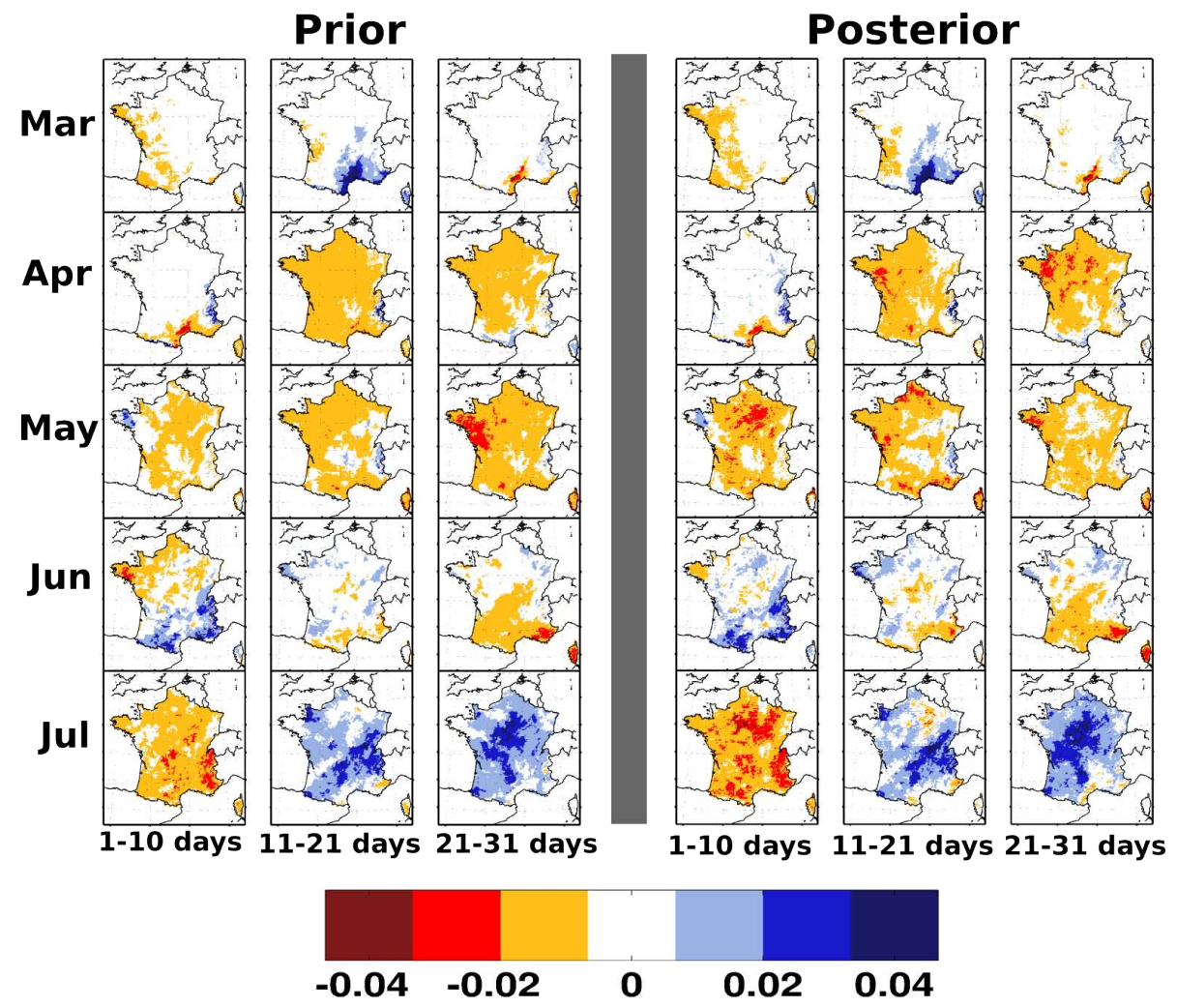

Fig. 12. Change rate calculated over a 10-day period for prior and posterior WG2 from March to July 2011 . The units are in $\mathrm{m}^{3} \mathrm{~m}^{-3}$. 


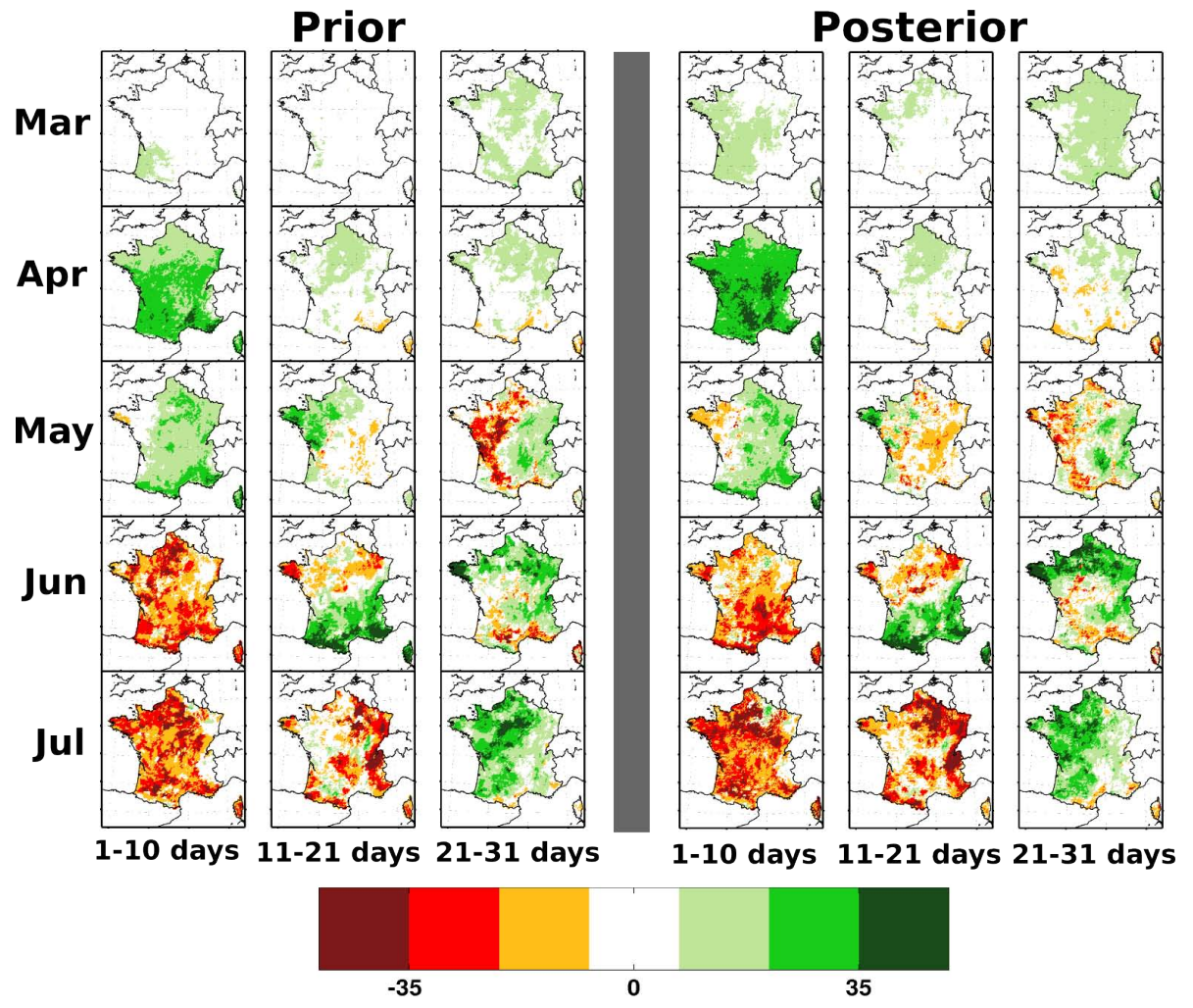

Fig. 13. Change rate calculated over a 10-day period for prior and posterior GPP from March to July 2011. The units are in $\mathrm{g} \mathrm{CO}_{2} \mathrm{~m}^{-2} \times 10$ days $^{-1}$.

analysis had a low impact. However, for all stations, the mean correlation is 0.82 without assimilation and 0.83 with assimilation. The anomaly correlations range between 0.3 and 0.7 . The short-term variability is improved for eight stations. On average, the anomaly correlation increases from 0.57 to 0.58 .

\section{Conclusions}

In the present study, a first attempt to use the multi-patch ISBA-A-gs land surface model in a multi-variate and multiscale EO data assimilation experiment at a regional scale was carried out. The France domain encompasses a wide variety of soil and vegetation ecosystems. At $8 \mathrm{~km}$ pixel scale, there is a high degree of heterogeneity that should be taken into account. Each grid cell is represented as a mosaic of 12 land covers or patches. The ISBA-A-gs LSM provides a detailed computation of the surface fluxes of energy, water and carbon at the sub-grid (patch) level and allows aggregating the information from different ecosystem types. Following this approach, a land data assimilation system was designed to produce the updated variables for each land cover by using one grid-scale observation. Taking into account the grid heterogeneity was central to this work and represented the main justification for including vegetation patches in the model and in the assimilation scheme. In the absence of a priori knowledge (such as agricultural practices) at the landscape scale, the assimilation approach employed in this study used the hypothesis that the distribution of innovations is proportional to the cover area. It was demonstrated that useful information can be extracted from the data signal at the grid level and distributed throughout the patch structure of the model.

The assimilation was performed over the domain of France for a period of $4 \mathrm{yr}$ from 2008 to 2011 using an extended Kalman filter in order to incorporate the SSM product derived from ASCAT together with the GEOV1 LAI satellite product. An important motivation for combining two sources of information within a land surface model is the expectation that they will contribute in a more coherent manner to reduce model uncertainties. At the same time, the use of different types of data at different resolutions may generate new challenges in the construction of an appropriate observation operator. However, it has been shown in this study that, even using a rather simple CDF matching procedure, meaningful information can be captured from the data and integrated into the model.

The model performance prior to assimilation was discussed in comparison with observations. Differences between observed and simulated LAI values were noticed at the beginning of the growing phase of the vegetation. An underestimation of photosynthesis under cold conditions together with a slight underestimation of the incoming solar radiation 
in the SAFRAN analysis (Szczypta et al., 2011), could contribute to the aforementioned differences. These discrepancies were identified as being partially responsible for a onemonth delay in the LAI seasonal cycle. The assimilation is able to significantly reduce this delay and, consequently, to increase the correlation between the model and the data by more than $30 \%$.

Errors affecting model simulations may be related to the distribution of bare soil and vegetation and may depend on the vegetation type. For example, croplands present more heterogeneities than grasslands and many processes of anthropogenic nature are not described for crops in the model. In this study, model errors were set to a single value for all patches. However, even under this simple assumption, the assimilation partly compensates for the lack of description of managed ecosystems by reducing the duration of the crop phenological cycle, which tends to be too long in the model. In the case of highly heterogeneous pixels, one has to be aware that this compensation may be not adequately distributed among the patches, especially in grid cells covering complex crop rotation systems. The choice of model error may be refined by assigning different error statistics to different ecosystems and making use of observed LAI at its original resolution of $1 \mathrm{~km}$. Assimilating original LAI data may help in decreasing the occurrence of sub-grid inconsistencies.

Nevertheless, the patch fraction, the Jacobian behaviour and the prescribed uncertainties in the model and in the observations offer the possibility of adapting the analysis to each plant functional type. In future developments, the LSM multi-patch structure may be used to account for additional information about the land use and management practices. For example, when an important reduction in LAI is observed over a short period of time in relation to a harvest, a specific distribution of the analysis increments could represent this additional information. The multi-patch assimilation may be viewed as an opportunity to include valuable sub-grid information from other sources in order to improve the analysis for the different patches.

The assimilation results also depend to a large extent upon the quality of the data to be assimilated. On the one hand, the data used in this study show potential within the land data assimilation. On the other hand, the remotely sensed SSM data exhibit a number of non-realistic low values associated with large uncertainties over densely vegetated areas (Kidd et al., 2013). This may be detrimental to analysis by causing a too-large soil moisture depletion. Nevertheless, this effect has been minimised due to the seasonal bias removal performed before the assimilation.

Many studies indicate the presence of systematic biases between the observations and the model outputs for soil moisture (Walker et al., 2003; De Lanoy et al., 2007) and LAI (Jarlan et al., 2008; Lafont et al., 2012). These biases have multiple origins related to model inputs, model physics or data retrieval procedures. Correcting only for the existing bias in observations without properly accounting for model uncertainties leads to suboptimal data assimilation results. The characterisation of errors associated with model dynamics and parameters is a rather challenging area for land data assimilation as mentioned by Reichle (2008). Even though model errors and parameter adjustment can be described with an EKF (Carrassi et al., 2012), ensemble approaches, which are becoming extensively used in Numerical Weather Prediction, offer a more flexible framework for addressing these questions in the case of a LSM as shown by Reichle et al. (2002b). The ensemble approaches should be examined in the future for land data assimilation together with particle filter technique. The latter is well suited for non-linear problems of small dimensions (van Leeuwen, 2009).

The impact of the assimilation upon carbon and water fluxes was also studied. It was shown that changes in LAI and soil moisture consistently influence the $\mathrm{CO}_{2}$ and water balances. The changes in the GPP fluxes produce smaller differences in their seasonal cycle than for the LAI, but they follow the same tendency with increased values in early spring and decreased values in autumn. The impact of the assimilation on evapotranspiration produces changes between 10 and $20 \%$. A noticeable fact is the reduction of the ET fluxes over large agricultural areas. In November and December, the assimilation provides positive soil moisture increments in the root-zone reservoir that causes a supply of water to be drained out. The increased drainage fluxes by assimilation together with the fact that the surface scheme ISBA has an excessive drainage rate (Decharme et al., 2011) indicate that the assimilation leads to important river discharge changes. (Draper et al., 2011) showed that the assimilation of the satellite-derived ASCAT soil moisture can improve runoff and river discharge simulations when assimilated in the operational hydro-meteorological model SAFRAN-ISBA-MODCOU (Habets et al., 2008). In a future study, the coupling of the ISBA-A-gs LSM and a hydrological model will be investigated.

A lagged response of vegetation to the soil moisture deficit in the root zone was pointed out. A single, thick root-zone soil layer represents the soil hydrology in the model version used in this study. Such description increases the time to deplete soil moisture causing this slow response to dry conditions. Also, the propagation of surface soil moisture information within deeper layers may be affected by the lack of vertical resolution of the model. In that respect, a multi-layer version of the soil hydrology is expected to improve the overall performance of the system. Increasing the number of soil layers will allow an explicit representation of a vertical distribution of the root profile in the soil and, subsequently, a more realistic vegetation response to water stress. Moreover, the short-term effects of the severe drought of 2011 on the vegetation development were analysed. It was shown that the assimilation helped the model to better respond to the drought conditions and also to react more efficiently to rainfall events after the drought period. This may be particularly useful in analysing the impact of extreme climate conditions. 
Acknowledgements. This work is a contribution to the Geoland2, IMAGINES and CORE-CLIMAX projects, co-funded by the European Commission within the Copernicus initiative in FP7. Constructive discussions with Clara Draper and Patricia de Rosnay are gratefully acknowledged.

Edited by: B. Su

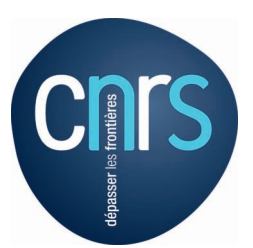

The publication of this article is financed by CNRS-INSU.

\section{References}

Albergel, C., Rüdiger, C., Pellarin, T., Calvet, J.-C., Fritz, N., Froissard, F., Suquia, D., Petitpa, A., Piguet, B., and Martin, E.: From near-surface to root-zone soil moisture using an exponential filter: an assessment of the method based on in-situ observations and model simulations, Hydrol. Earth Syst. Sci., 12, 1323-1337, doi:10.5194/hess-12-1323-2008, 2008.

Albergel, C., Calvet, J.-C., Gibelin, A.-L., Lafont, S., Roujean, J.L., Berne, C., Traullé, O., and Fritz, N.: Observed and modelled ecosystem respiration and gross primary production of a grassland in southwestern France, Biogeosciences, 7, 1657-1668, doi:10.5194/bg-7-1657-2010, 2010.

Barbu, A. L., Calvet, J.-C., Mahfouf, J.-F., Albergel, C., and Lafont, S.: Assimilation of Soil Wetness Index and Leaf Area Index into the ISBA-A-gs land surface model: grassland case study, Biogeosciences, 8, 1971-1986, doi:10.5194/bg-8-1971-2011, 2011.

Baret, F., Hagolle, O., Geiger, B., Bicheron, P., Miras, B., Huc, M., Berthelot, B., Weiss, M., Samain, O., Roujean, J. L., and Leroy, M.: LAI, fAPAR and fCover CYCLOPES global products derived from VEGETATION, Part 1: Principles of the algorithm, Remote Sens. Environ., 110, 275-286, 2007.

Baret, F., Weiss, M., Lacaze, R., Camacho, F., Makhmarad, H., Pacholczyk, P., and Smetse, B.: GEOV1: LAI, FAPAR essential climate variables and FCOVER global time series capitalizing over existing products, Part 1: Principles of development and production, Remote Sens. Environ., 137, 299-309, doi:10.1016/j.rse.2012.12.027, 2013.

Bartalis, Z., Wagner, W., Naeimi, V., Hasenauer, S., Scipal, K., Bonekamp, H., Figa, J., and Anderson, C.: Initial soil moisture retrievals from the METOP-A advanced Scatterometer (ASCAT), Geophys. Res. Lett., 34, L20401, doi:10.1029/2007GL031088, 2007.

Bolten, J. D. and Crow, W. T.: Improved prediction of quasi-global vegetation conditions using remotely-sensed surface soil moisture, Geophys. Res. Lett., 39, L19406, doi:10.1029/2012GL053470, 2012.

Boone, A., Calvet, J.-C., and Noilhan, J.: Inclusion of a third soi layer in a land surface scheme using the force-restore method, J. Appl. Meteorol., 38, 1611-1630, 1999.
Brut, A., Rüdiger, C., Lafont, S., Roujean, J.-L., Calvet, J.-C., Jarlan, L., Gibelin, A.-L., Albergel, C., Le Moigne, P., Soussana, J.-F., Klumpp, K., Guyon, D., Wigneron, J.-P., and Ceschia, E.: Modelling LAI at a regional scale with ISBA-A-gs: comparison with satellite-derived LAI over southwestern France, Biogeosciences, 6, 1389-1404, doi:10.5194/bg-6-1389-2009, 2009.

Calvet, J.-C.: Investigating soil and atmospheric plant water stress using physiological and micrometeorological data sets, Agr. Forest Meteorol., 103, 229-247, 2000.

Calvet, J.-C. and Noilhan J.: From near-surface to root-zone soil moisture using year-round data, J. Hydrometeorol., 1, 393-411, 2000.

Calvet, J.-C., Noilhan, J., Roujean, J.-L., Bessemoulin, P., Cabelguenne, M., Olioso, A., and Wigneron, J.-P.: An interactive vegetation SVAT model tested against data from six contrasting sites, Agr. Forest Meteorol., 92, 73-95, 1998.

Calvet, J.-C., Rivalland, V., Picon-Cochard, C., and Guelh, J.M.: Modelling forest transpiration and $\mathrm{CO}_{2}$ fluxes-response to soil moisture stress, Agr. Forest Meteorol., 124, 143-156, doi:10.1016/j.agrformet.2004.01.007, 2004.

Calvet, J.-C., Fritz, N., Froissard, F., Sequia, D., Petitpa, A., and Piguet, B.: In situ soil moisture observations for the CAL/VAL of SMOS: the SMOSMANIA network, International Geoscience and Remote Sensing Symposium, IGARSS, Barcelona, Spain, 23-28 July 2007, 1196-1199, doi:10.1109/IGARSS.2007.4423019, 2007.

Calvet, J.-C., Lafont, S., Cloppet, E., Souverain, F., Badeau, V., and Le Bas, C.: Use of agricultural statistics to verify the interannual variability in land surface models: a case study over France with ISBA-A-gs, Geosci. Model Dev., 5, 37-54, doi:10.5194/gmd-537-2012, 2012.

Camacho, F., Cernicharo, J., Lacaze, R., Baret, F., and Weiss, M.: GEOV1: LAI, FAPAR essential climate variables and FCOVER global time series capitalizing over existing products, Part 2: Validation and intercomparison with reference product, Remote Sens. Environ., 137, 310-329, doi:10.1016/j.rse.2013.02.030, 2013.

Carrassi, A., Hamdi, R., Termonia, P., and Vannitsem, S.: Short term augmented extended Kalman filter for soil analysis: a feasibility study, Atmos. Sci. Lett., 13, 268-274, 2012.

Ciais, P., Reichstein, M., Viovy, N., Granier, A., Ogée, J., Allard, V., Aubinet, M., Buchmann, N., Bernhofer, C., Carrara, A., Chevallier, F., De Noblet, N., Friend, A. D., Friedlingstein, P., Grünwald, T., Heinesch, B., Keronen, P., Knohl, A., Krinner, G., Loustau, D., Manca, G., Matteucci, G., Miglietta, F., Ourcival, J. M., Papale, D., Pilegaard, K., Rambal, S., Seufert, G., Soussana, J. F., Sanz, M. J., Schulze, E. D., Vesala, T., and Valentini, R.: Europe-wide reduction in primary productivity caused by the heat and drought in 2003, Nature, 437, 529-533, doi:10.1038/nature03972, 2005.

Decharme, B., Boone, A., Delire, C., and Noilhan, J.: Local evaluation of the Interaction between Soil Biosphere Atmosphere soil multilayer diffusion scheme using four pedotransfer functions, J. Geophys. Res., 116, D20126, doi:10.1029/2011JD016002, 2011.

de Jeu, R. A. M., Wagner, W., Holmes, T. R. H., Dolman, A. J., van de Giesen, N. C., and Friesen, J.: Global soil moisture patterns observed by space borne microwave radiometers and scatterometers, Surv. Geophys., 29, 399-420, 2008. 
De Lannoy, G. J. M., Reichle, R. H., Houser, P. R., Pauwels, V. R. N., and Verhoest, N. E. C.: Correcting for forecast bias in soil moisture assimilation with the ensemble Kalman filter, Water Resour. Res., 43, W09410, doi:10.1029/2006WR005449, 2007.

Demarty, J., Chevallier, F., Friend, A. D., Viovy, N., Piao, S., and Cias, P.: Assimilation of global MODIS leaf area index retrievals within a terrestrial biosphere model, Geophys. Res. Lett., 34, L15402, doi:10.1029/2007GL030014, 2007.

De Rosnay, P., Drusch, M., Vasiljevic, D., Balsamo, G., Albergel, C., and Isaksen, L.: A simplified Extended Kalman Filter for the global operational soil moisture analysis at ECMWF, Q. J. Roy. Meteorol. Soc., 139, 1199-1213, doi:10.1002/qj.2023, 2013.

Dharssi, I., Bovis, K. J., Macpherson, B., and Jones, C. P.: Operational assimilation of ASCAT surface soil wetness at the Met Office, Hydrol. Earth Syst. Sci., 15, 2729-2746, doi:10.5194/hess15-2729-2011, 2011

Draper, C. S., Mahfouf, J.-F., and Walker, W.: An EKF assimilation of AMSR-E soil moisture into the ISBA land surface scheme, J. Geophys. Res., 114, D20104, doi:10.1029/2008JD011650, 2009.

Draper, C., Mahfouf, J.-F., Calvet, J.-C., Martin, E., and Wagner, W.: Assimilation of ASCAT near-surface soil moisture into the SIM hydrological model over France, Hydrol. Earth Syst. Sci., 15, 3829-3841, doi:10.5194/hess-15-3829-2011, 2011.

Fang, H., Jiang, C., Li, W., Wei, S., Baret, F., Chen, J. M., GarciaHaro, J., Liang, S., Liu, R., and Myneni, R., Pinty, B., Xiao, Z., and Zhu, Z.: Characterization and intercomparison of global moderate resolution leaf area index (LAI) products: Analysis of climatologies and theoretical uncertainties, J. Geophys. Res.Biogeo., 118, 1-20, doi:10.1002/jgrg.20051, 2013.

Faroux, S., Kaptué Tchuenté, A. T., Roujean, J.-L., Masson, V., Martin, E., and Le Moigne, P.: ECOCLIMAP-II/Europe: a twofold database of ecosystems and surface parameters at $1 \mathrm{~km}$ resolution based on satellite information for use in land surface, meteorological and climate models, Geosci. Model Dev., 6, 563582, doi:10.5194/gmd-6-563-2013, 2013

Gu, Y., Belair, S., Mahfouf, J. F., and Deblonde, G.: Optimal interpolation analysis of leaf area index using MODIS data, Remote Sens. Environ., 104, 283-296, doi:10.1016/j.rse.2006.04.021, 2006.

Habets, F., Boone, A., Champeaux, J.-L., Etchevers, P., Franchistéguy, L., Leblois, E., Ledoux, E., Le Moigne, P., Martin, E., Morel, S., Noilhan, J., and Quintana-Seguì, P.: The SAFRAN-ISBA-MODCOU hydrometeorological model applied over France, J. Geophys. Res., 113, D06113, doi:10.1029/2007JD008548, 2008.

Hirschi, M., Seneviratne, S. I., Alexandrov, V., Boberg, F., Boroneant, C., Christensen, O. B., Formayer, H., Orlowsky, B., and Stepanek, P.: Observational evidence for soil-moisture impact on hot extremes in southeastern Europe, Nat. Geosci., 4, 17-21, doi:10.1038/ngeo1032, 2011.

Houser, P. R., Shuttleworth, W. J., Famiglietti, J. S., Gupta, H. V., Syed, K. H., and Goodrich, D. C.: Integration of soil moisture remote sensing and hydrologic modelling using data assimilation, Water Resour. Res., 34, 3405-3420, doi:10.1029/1998WR900001, 1998.
Jarlan, L., Balsamo, G., Lafont, S., Beljaars, A., Calvet, J.-C., and Mougin, E.: Analysis of leaf area index in the ECMWF land surface model and impact on latent heat on carbon fluxes: application to West Africa, J. Geophys. Res., 113, D24117, doi:10.1029/2007JD009370, 2008.

Kaminski, T., Knorr, W., Scholze, M., Gobron, N., Pinty, B., Giering, R., and Mathieu, P.-P.: Consistent assimilation of MERIS FAPAR and atmospheric $\mathrm{CO}_{2}$ into a terrestrial vegetation model and interactive mission benefit analysis, Biogeosciences, 9, 3173-3184, doi:10.5194/bg-9-3173-2012, 2012.

Kato, T., Knorr, W., Scholze, M., Veenendaal, E., Kaminski, T., Kattge, J., and Gobron, N.: Simultaneous assimilation of satellite and eddy covariance data for improving terrestrial water and carbon simulations at a semi-arid woodland site in Botswana, Biogeosciences, 10, 789-802, doi:10.5194/bg-10-789-2013, 2013.

Kidd, R., Makhmara, H., and Paulik, C.: GIO GL1 PUM SWI I1.00.pdf, 25 pp. available at: http://land.copernicus.eu/global/ products/SWI/Documents/ProductUserManual (last access: January 2014), 2013.

Koster, R. D. and Suarez, M. J.: Modeling the land surface boundary in climate modls as a composite of independent vegetation stands, J. Geophys. Res., 97, 2697-2715, 1992.

Lafont, S., Zhao, Y., Calvet, J.-C., Peylin, P., Ciais, P., Maignan, F., and Weiss, M.: Modelling LAI, surface water and carbon fluxes at high-resolution over France: comparison of ISBA-A-gs and ORCHIDEE, Biogeosciences, 9, 439-456, doi:10.5194/bg9-439-2012, 2012

Le Moigne, P., Boone, A., Calvet, J.-C., Decharme, B., Faroux, S., Gibelin, A.-L., Lebeaupin, C., Mahfouf, J.-F., Martin, E., Masson, V., Mironov, D., Noilhan, J., Tulet, P., and Van Den Hurk, B.: SURFEX scientific documentation, Groupe de météorologie à moyenne échelle, note de centre, 87, Meteo-France, Toulouse, 211 pp., 2009

Mahfouf, J.-F.: Assimilation of satellite-derived soil moisture from ASCAT in a limited-area NWP model, Q. J. Roy. Meteorol. Soc., 136, 784-798, doi:10.1002/qj.602, 2010.

Mahfouf, J.-F., Bergaoui, K., Draper, C., Bouyssel, F., Taillefer, F., and Taseva, L.: A comparison of two off-line soil analysis schemes for assimilation of screen level observations, J. Geophys. Res., 114, D08105, doi:10.1029/2008JD011077, 2009.

Montzka, C., Pauwels, R. N. V., Franssen, H.-J. H., Han, X., and Vereecken, H.: Multivariate and multiscale data assimilation in terrestrial systems: a review, Sensors, 12, 16291-16333, 2012.

Myneni, R. B., Hoffman, S., Knyazikhin, Y., Privette, J. L., Glassy, J., Tian, Y., Wang, Y., Song, X., Zhang, Y., Smith, G. R., Lotsch, A., Friedl, M., Morisette, J. T., Votava, P., Nemani, R. R., and Running, S. W.: Global products of vegetation leaf area and fraction of absorbed PAR from one year of MODIS data, Remote Sens. Environ., 83, 214-231, 2002.

Nearing, G. S., Crow, W. T., Thorp, K. R., Moran, M. S., Reichle, R., and Gupta, H. V.: Assimilating remote sensing observations of leaf area index and soil moisture for wheat yield estimates: An observing system simulation experiment, Water Resour. Res. 48, W05525, doi:10.1029/2011WR011420, 2012.

Noilhan, J. and Mahfouf, J.-F.: The ISBA land surface parameterisation scheme, Global Planet. Change, 13, 145-149, 1996. 
Pauwels, V. R. N., Verhoest, N. E. C., De Lannoy, G. J. M., Guissard, V., Lucau, C., and Defourny, P.: Optimization of a coupled hydrology-crop growth model through the assimilation of observed soil moisture and leaf area index values using an ensemble Kalman filter, Water Resour. Res., 43, W04421, doi:10.1029/2006WR004942, 2007.

Quintana-Segui, P., Lemoigne, P., Durand, Y., Martin, E., Habets, F., Baillon, M., Canellas, C., Franchistéguy, L., and Morel, S.: Analysis of near surface atmospheric variables: Validation of the SAFRAN analysis over France, J. Appl. Meteorol. Clim., 47, 92107, 2008.

Reichle, R. H.: Data assimilation methods in the Earth sciences, Adv. Water Resour., 31, 1411-1418, doi:10.1016/j.advwatres.2008.01.001, 2008.

Reichle, R. H., McLaughlin, D. B., and Entekhabi, D.: Hydrologic data assimilation with the ensemble Kalman filter, Mon. Weather Rev., 130, 103-144, 2002a.

Reichle, R. H., Walker, J. P., Koster, D., and Houser, P. R.: Extended versus Ensemble Kalman Filtering for Land Data Assimilation, J. Hydrometeorol., 3, 728-740, 2002 b.

Reichstein, M., Papale, D., Valentini, R., Aubinet, M., Bernhofer, C., Knohl, A., Laurila, T., Lindroth, A., Moors, E., Pilegaard, K., and Seufer, G.: Determinants of terrestrial ecosystem carbon balance inferred from European eddy covariance flux sites, Geophys. Res. Lett., 34, L01402, doi:10.1029/2006GL027880, 2007.

Rüdiger, C., Albergel, C., Mahfouf, J.-F., Calvet, J.-C., and Walker, J. P.: Evaluation of Jacobians for Leaf Area Index data assimilation with an extended Kalman filter, J. Geophys. Res., 115, D09111, doi:10.1029/2009JD012912, 2010.

Sabater, J. M., Rüdiger, C., Calvet, J.-C., Fritz, N., Jarlan, L., and Kerr, Y.: Joint assimilation of surface soil moisture and LAI observations into land surface model, Agr. Forest Meteorol., 148, 1362-1373, doi:10.1016/j.agrformet.2008.04.003, 2008.

Scipal, K., Drusch, M., and Wagner, W.: Assimilation of a ERS scatterometer derived soil moisture index in the ECMWF numerical weather prediction system, Adv. Water Resour., 31, 1101-1112, doi:10.1016/j.advwatres.2008.04.013, 2008.
Seneviratne, S. I., Corti, T., Davin, E. L., Hirschi, M., Jaeger, E. B., Lehner, I., Orlowsky, B., and Teuling, A. J.: Investigating soil moisture-climate interactions in a changing climate: a review, Earth-Sci. Rev., 99, 125-161, doi:10.1016/j.earscirev.2010.02.004, 2010.

Sepulcre-Canto, G., Horion, S., Singleton, A., Carrao, H., and Vogt, J.: Development of a Combined Drought Indicator to detect agricultural drought in Europe, Nat. Hazards Earth Syst. Sci., 12, 3519-3531, doi:10.5194/nhess-12-3519-2012, 2012.

Szczypta, C., Calvet, J.-C., Albergel, C., Balsamo, G., Boussetta, S., Carrer, D., Lafont, S., and Meurey, C.: Verification of the new ECMWF ERA-Interim reanalysis over France, Hydrol. Earth Syst. Sci., 15, 647-666, doi:10.5194/hess-15-647-2011, 2011.

Szczypta, C., Decharme, B., Carrer, D., Calvet, J.-C., Lafont, S., Somot, S., Faroux, S., and Martin, E.: Impact of precipitation and land biophysical variables on the simulated discharge of European and Mediterranean rivers, Hydrol. Earth Syst. Sci., 16, 3351-3370, doi:10.5194/hess-16-3351-2012, 2012.

van der Molen, M. K., Dolman A. J., Ciais, P., Eglin, T., Gobron, N., Law, B. E., Meir, P., Peters, W., Phillips, O. L., Reichstein, M., Chen, T., Dekker, S. C., Doubková, M., Friedl, M. A., Jung, M., van den Hurk, B. J. J. M., de Jeu, R. A. M., Kruijt, B., Ohta, T., Rebel, K. T., Plummer, S., Seneviratne, S. I., Sitch, S., Teuling, A. J., van der Werf, G. R., and Wang, G.: Drought and ecosystem carbon cycling, Agr. Forest Meteorol., 151, 765-773, doi:10.1016/j.agrformet.2011.01.018, 2011.

van Leeuwen, P. J.: Particle filtering in geophysical systems, Mon. Weather Rev., 137, 4089-4114, 2009.

Wagner, W., Lemoine, G., and Rott, H.: A method for estimating soil moisture from ERS scatterometer and soil data, Remote Sens. Environ., 70, 191-207, 1999.

Walker, J. P., Houser, P. R., and Reichle, R.: New technologies require advances in hydrologic data assimilation, EOS T. Am. Geophys. Un., 84, 545-551, 2003. 